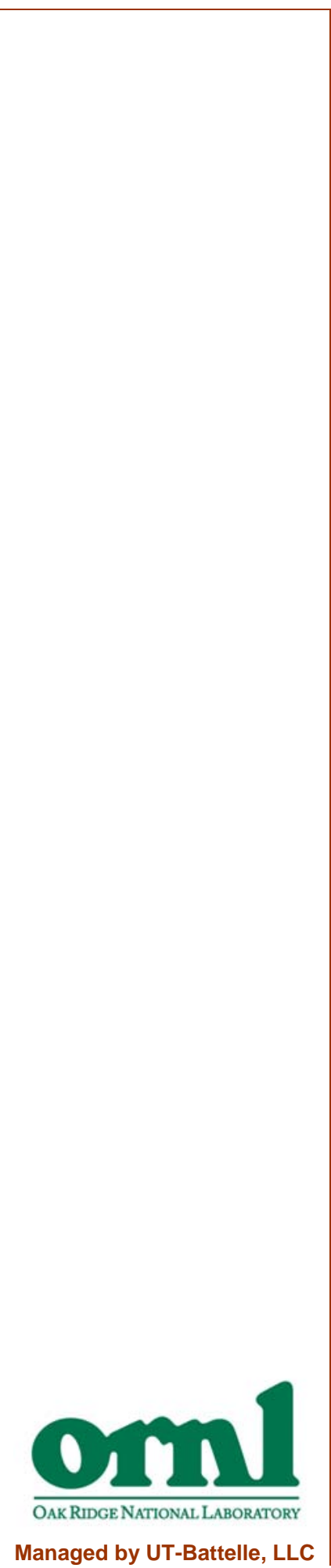

Final Technical Report Addendum

Characterization of Min-K TE-1400 Thermal Insulation (Two-Year Gradient Stress Relaxation Testing Update)

September 2009

Principal Investigators:

Dr. J. G. Hemrick

Dr. E. Lara-Curzio

Oak Ridge National Laboratory 


\section{DOCUMENT AVAILABILITY}

\section{Reports produeed after Jantury 1, 1996, are generally available free vija the U.S.}

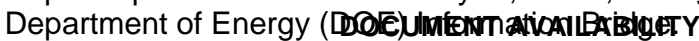

Reports produced after January 1, 1996, are generally available free via the U.S. DepartWeq of

Reports produced before January 1, 1996, may be purchased by members of the public from the following source.

Reports produced before January 1,1996, may be purchased by members of the

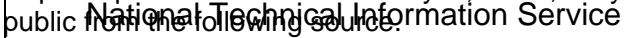
5285 Port Royal Road

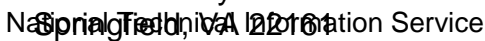

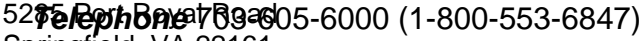

Spribafied

Tetephope $-603-6050000$ (1-800-553-6847)

TDD-m3 48 - 4639 is fedworld.gov

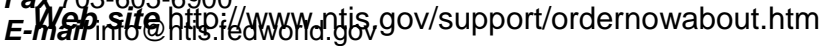

Web site http://www.ntis.gov/support/ordernowabout.htm

Reports are available to DOE employees, DOE contractors, Energy Technology Data

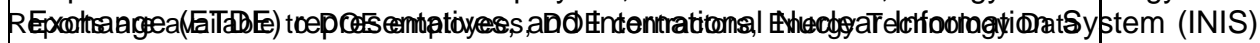
ExeppegentEtiDes frephet (INIS) representatives from the following source.

Office of Scientific and Technical Information

Offics of Scientific and Technical Information

P.

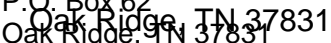

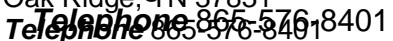

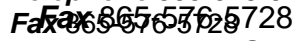

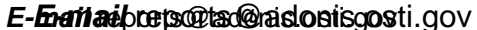

Web site http://www.osthgeb/ediffaltțith/hwww.osti.gov/contact.html 


\section{FINAL TECHNICAL REPORT ADDENDUM}

Project Title: $\quad$ Characterization of Min-K TE-1400 Thermal Insulation

Project Period: $\quad$ August 2007 - July 2008

PI(s): $\quad$ Dr. J. G. Hemrick

(865) 776-0758

hemrickjg@ornl.gov

Dr. E. Lara-Curzio

(865) 574-1749

laracurzioe@ornl.gov

Recipient: $\quad$ Oak Ridge National Laboratory (ORNL)

Bethel Valley Road

P. O. Box 2008

Oak Ridge, TN 37831

Subcontractor

Oak Ridge National Laboratory (ORNL)

Bethel Valley Road

P.O. Box 2008

Oak Ridge, TN 37831 

ORNL/TM-2008/157

\title{
Characterization of Min-K TE-1400 Thermal Insulation
}

\author{
James G. Hemrick ${ }^{1}$, Edgar Lara-Curzio ${ }^{1}$, and James F. King ${ }^{1}$
}

September 2009

\author{
Prepared by \\ OAK RIDGE NATIONAL LABORATORY \\ P.O. Box 2008 \\ Oak Ridge, Tennessee 37831-6283 \\ managed by \\ UT-Battelle, LLC \\ for the \\ U.S. DEPARTMENT OF ENERGY \\ under contract DE-AC05-00OR22725
}

\footnotetext{
${ }^{1}$ Oak Ridge National Laboratory, Material Science and Technology Division, Oak Ridge, TN
} 


\section{Table of Contents}

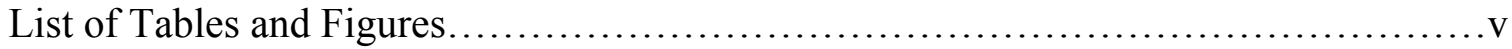

Abbreviations and Acronyms.................................................. vii

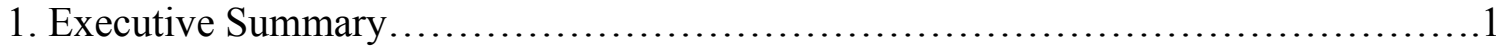

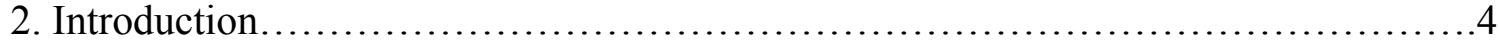

3. Gradient Stress Relaxation Testing ..........................................4

3.1 Experimental Procedures.............................................4

3.2 Results...............................................................6

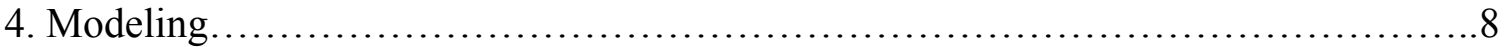

5. Lessons Learned.......................................................... 10

6. Acknowledgements..................................................... 11

Tables and Figures.......................................................

Appendix 1 Min-K Testing and Characterization Test Matrix: Preliminary Compression Tests....................................................... 31

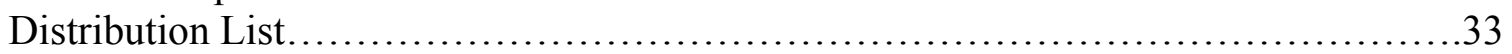




\section{List of Tables and Figures}

\section{Tables}

Table 1. Stress Relaxation Test Matrix..........................................13

Table 2. Additional Long-Term Gradient Stress Relaxation Testing Matrix.

\section{Figures}

Figure 1. Gradient Stress Relaxation Test Frame...................................13

Figure 2. Installed Back-Up Power Supply System for Gradient Test Systems...........14

Figure 3. Picture of Modified Gradient Stress Relaxation Test Frame....................14

Figure 4. Results from $700 / 100^{\circ} \mathrm{C}$ Gradient Stress Relaxation Test (Test \#13)..........15

Figure 5. Results from $700 / 100^{\circ} \mathrm{C}$ Gradient Stress Relaxation Test (Test \#15)............15

Figure 6. Results from $700 / 100^{\circ} \mathrm{C}$ Gradient Stress Relaxation Test (Test \#15) TSE

Testing ............................................................... 16

Figure 7. Results from $1,100 / 300^{\circ} \mathrm{F}$ Gradient Stress Relaxation Test...................16

Figure 8. Results from $1,000 / 160^{\circ} \mathrm{F}$ Gradient Stress Relaxation Test....................17

Figure 9. . Results from $900^{\circ} \mathrm{F}-\left(\approx 50^{\circ} \mathrm{F}\right)$ Gradient Stress Relaxation Test................ 17

Figure 10. Log Function Curve Fits of One-Year Long-Term Gradient Stress Relaxation Data (a - Test \#13, b - Test \#15)................................18

Figure 11. Log Function Curve Fits of Two-Year Long-Term Gradient Stress

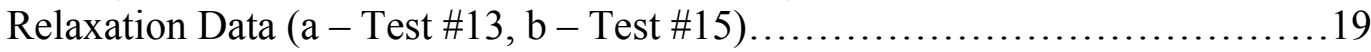

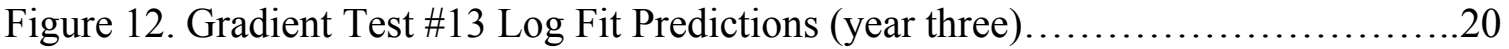

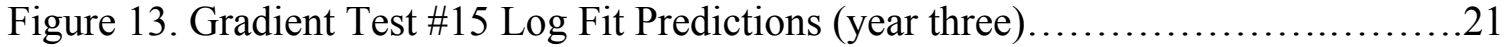

Figure 14. Gradient Test \#13 Log Fit Predictions (year four) .........................22

Figure 15. Gradient Test \#15 Log Fit Predictions (year four).........................23

Figure 16. Log Function Curve Fits of Long-Term Gradient Stress Relaxation Data

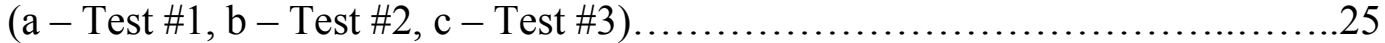

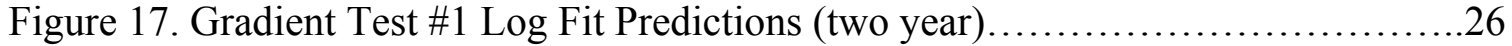

Figure 18. Gradient Test \#2 Log Fit Predictions (two year)...........................27

Figure 19. Gradient Test \#3 Log Fit Predictions (two year)...........................28

Figure 20. Change in Log-Log Fit Coefficients ( $\mathrm{a}$ and $\mathrm{b}$ ) and Fit Parameter (R) with Respect to Duration of Data Used for Curve Fit..............................30 
Abbreviations and Acronyms

DOE U.S. Department of Energy

KWW Kohlrausch-Williams-Watts

ORNL Oak Ridge National Laboratory

TSE Transient Strain Events

NOTE: Units used in this document are those requested by the program sponsors. Where applicable, equivalent SI units are given. 

1. Executive Summary

Min-K 1400TE ${ }^{2}$ insulation material was characterized at Oak Ridge National Laboratory for use in structural applications under gradient temperature conditions. A previous report (ORNL/TM-2008/089) discusses the testing and results from the original three year duration of the project. This testing included compression testing to determine the effect of sample size and test specimen geometry on the compressive strength of Min-K, subsequent compression testing on cylindrical specimens to determine loading rates for stress relaxation testing, isothermal stress relaxation testing, and gradient stress relaxation testing.

Initial gradient stress relaxation testing was completed, although under slightly different thermal conditions than those originally proposed $850 / 450^{\circ} \mathrm{C}$ and $450 / 190^{\circ} \mathrm{C}$ with a maximum initial stress of 100 and $200 \mathrm{psi}(690$ and $1380 \mathrm{kPa})$. The duration of these tests spanned between 100 and 1300 hours. Following completion of the initial isothermal and gradient temperature stress relaxation testing, an effort was undertaken to convert two mechanical testing frames with a set-up to conduct isothermal stress relaxation tests to perform gradient stress relaxation tests and to improve the robustness of the gradient stress relaxation test set-up in an effort to complete tests of sixmonth to one-year duration. To facilitate this, the test frames were retrofitted with new heater platens, improved thermal insulation, improved electrical connections, and a backup power supply system to run all four retrofitted test frames. Temperature gradients for new testing consisted of $700 / 100^{\circ} \mathrm{C}$ ( 5 tests) and $800 / 190^{\circ} \mathrm{C}$ ( 1 test) with initial loads of $200 \mathrm{psi}(1380 \mathrm{kPa})$. Loading was performed under strain control utilizing a twelve-step loading scheme with loading every half hour at a rate of $5.56 \%$ strain/hour. Loading was followed by stress relaxation under constant strain with testing scheduled to be carried out for six-months (4,400 hours) and possibly extended to one-year ( 8,760 hours). Oneyear results of these tests are discussed in the previously published report (ORNL/TM2008/089).

Of the tests describe above, two were continued past the one-year mark. These were Gradient Test $\# 13$ and $\# 15$, both with $700 / 100^{\circ} \mathrm{C}$ temperature gradients. At the time of the writing of the previous report, Test \#13 had been running for over one year with over 10,050 hours of exposure and a current stress level of $105 \mathrm{psi}(724 \mathrm{kPa})$. This test was continued during year four for a total test duration of 18,135 hours and the final stress level was 92 psi $(634 \mathrm{kPa})$. Because of malfunction of the machine crosshead, this test was simply terminated instead of being unloaded and cooled. At the time of the writing of the previous report, Test \#15 had been running unaltered for over one year with over 9,735 hours of exposure and a current stress level of $126 \mathrm{psi}(869 \mathrm{kPa})$. The test was continued during year four for a total test duration of 17,935 hours and the final stress level was 120 psi $(827 \mathrm{kPa})$. Following completion of the test, Transient Strain Event (TSE) testing was performed on this sample before it was cooled to room temperature.

In parallel to the above long-term gradient stress relaxation testing, three additional tests were started with the intent of obtaining data of one-year duration under a variety of temperature gradients ranging from $1100^{\circ} \mathrm{F}\left(593^{\circ} \mathrm{C}\right)$ down to room temperature and an

${ }^{2}$ Thermal Ceramics, Augusta, Georgia 
initial load of $7812 \mathrm{lbf}(155-158 \mathrm{psi}, 1069-1089 \mathrm{kPa})$. Existing test frames were refurbished and retrofitted with modified heater platens, improved thermal insulation, improved electrical connections, and a back-up power supply system.

The three additional stress relaxation tests ran on the refurbished, modified mechanical test frames previously all reached one-year of test duration as described in the previous report (ORNL/TM-2008/089). The first test, which was started in April of 2006, had a gradient of $1,100 / 300^{\circ} \mathrm{F}$ and an initial loading of 7,812 lbf (155 psi). At the one-year mark (April 2007), this test had relaxed to $96 \mathrm{psi}(662 \mathrm{kPa})$. This test was continued until July of 2008 at which time it had been running for 19,650 hours and had reached a stress level of $84 \mathrm{psi}(579 \mathrm{kPa})$. At the conclusion of the test, the sample was unloaded at a constant rate of $1.0 \%$ per hour until the current stress was reduced to $9.21 \mathrm{psi}(64 \mathrm{kPa})$, which corresponded to a reduction in strain from 11.44 to $8.92 \%$. Following the reduction in strain, the sample was held under constant displacement over night (20.5 hours) during which the stress increased from 9.21 to $10.70 \mathrm{psi}$ (64 to $74 \mathrm{kPa}$ ). The sample was then fully unloaded at the same constant rate of $1.0 \%$ per hour, followed by cooling of the sample. The second test, which was also started in April of 2006, had a gradient of $1,000 / 160^{\circ} \mathrm{F}$ and an initial loading of 7,812 lbf (158 psi). At the one-year mark (April 2007), Test \#2 had relaxed to $115 \mathrm{psi}(793 \mathrm{kPa})$. This test was continued until April of 2008 when it was ended due to a computer failure. At the time of the failure, this test had been running for over 17,375 hours and was at a stress level of $100 \mathrm{psi}(689 \mathrm{kPa})$. The third test, which was started in May 2006, had a gradient of $900 / \approx 50^{\circ} \mathrm{F}$ and an initial loading of 7,812 lbf (157 psi). At the one-year mark (May 2007), Test \#3 had relaxed to 119 psi $(820 \mathrm{kPa})$. This test was continued until July of 2008 at which time it had been running for 18,455 hours and had reached a stress level of $116 \mathrm{psi}(800 \mathrm{kPa})$. At the conclusion of the test, the sample was unloaded at a constant rate of $1.0 \%$ per hour until half the current strain was removed (this corresponded to a reduction in strain from approximately 3.6 to $1.8 \%)$. This resulted in a reduction of stress to $45.37 \mathrm{psi}(313 \mathrm{kPa})$. Following the reduction in strain, the sample was held under constant displacement over night (19.5 hours) during which time the stress increased from 45.37 to $46.62 \mathrm{psi}$ (313 to $321 \mathrm{kPa}$ ). The sample was then fully unloaded at the same constant rate of $1.0 \%$ per hour, followed by cooling to ambient temperature.

Previously, during the long term gradient stress relaxation testing, data were fitted with an exponential model and compared with predictions made using isothermal stress relaxation data. Data were also fitted with the previously derived ORNL mathematical model, a Maxwell model, and a KWW model. These fits were updated weekly as new data became available to evaluate convergence of each model. Subsequent modeling with data in excess of one-year duration was also pursued. It was found that a simple log function $(\mathrm{y}=\mathrm{a}-\mathrm{b} * \log (\mathrm{x}))$ best described the long-term gradient stress relaxation data. Where $\mathrm{y}$ is the normalized stress and $\mathrm{x}$ is time. In all cases, an $\mathrm{R}$ value of 0.98 was obtained using this function. After obtaining two year duration data, the same log function was again used to fit the data. In all cases, an $\mathrm{R}$ value of greater than 0.97 was obtained using this function. 
Also, previously the effect of fitting various time scales of data for predicting long term behavior was investigated. Fits were made using the same simple log function as above using data from 1,000, 2,500, 5,000, 7,500, and 9,000 hours. In each case, predictions were made out to 10,000 and 50,000 hours. From this analysis, it appeared that data between 5,000 and 7,500 hours was sufficient to predict behavior out to 10,000 hours. Data of less than 5,000 hours tended to under predict the stress relaxation. Data of greater than 7,500 hours accurately predicted the stress relaxation, but did not provide any improvement in the prediction. Therefore it was hypothesized that it may not be necessary to extend testing to this duration, even for predictions out to 50,000 hours.

A similar investigation of the effect of fitting various time scales of data for predicting long term behavior was repeated with the two-year duration data. Analysis incorporating the new data out to 17,500 hours found that at 10,000 hours the predictions of the 7,500 and 12,500 hour fits were the best. For Test \#13, no increase in accuracy was seen for the 15,000 hour fit and a decrease in accuracy was seen for the 17,500 hour fit. For Test \#15, fits of data less than 7,500 hours tended to under predict and fits of data greater than 12,500 hours tended to over predict the stress. The same kind of analysis as reported in the previous report (ORNL/TM-2008/089) was repeated with data at 17,500 hours. For Test \#13, all predictions over estimated the remaining stress in the sample with the 15,000 and 17,500 hour predictions being the closest (errors of 4.69 and $6.25 \%$, respectively), followed by the 5,000 and 2,500 hour predictions (errors of 6.70 and $6.92 \%$, respectively). The predictions for Test \#15 where found to be much better. Predictions made with 5,000 hours of data or less under predicted the remaining stress and predictions made with 7,500 hours of data or more over predicted the remaining stress. The 12,500 hour prediction was the closest with an error of $0.52 \%$, closely followed by the predictions with 7,000 and 10,000 hours of data (errors of 0.54 and $0.62 \%$, respectively).

Mathematical modeling of the Min-K stress relaxation behavior exhibited by the additional long-term gradient stress relaxation testing under a variety of temperature gradients was also performed. The same simple $\log$ function $(\mathrm{y}=\mathrm{a}-\mathrm{b} * \log (\mathrm{x}))$ utilized above was used to fit the long-term gradient stress relaxation data obtained. In each case, an $\mathrm{R}$ value of 0.90 or greater was obtained using this function.

Also, similar to above an investigation of the effect of fitting various time scales of data for predicting long-term behavior was performed. Analysis out to 17,500 hours (out to 12,500 hours for Test \#2) was carried out to determine the accuracy of the various fits to predict actual test data. For Test $\# 1$, all predictions over estimated the remaining stress in the sample with the 5,000 and 7,500 hour predictions being the closest (errors of 4.89 and $5.17 \%$, respectively), followed by the 17,500,10,000 and 12,500 hour predictions (errors of 5.28, 5.51, and 5.54\%, respectively). For Test \#2, all predictions were very close, but the prediction made with 12,500 hours of data was the closest (error of $0.02 \%$ ), followed by predictions made with 10,000 hour and 1,000 hour data (errors of -0.16 and $0.32 \%$, respectively). For Test \#3, predictions were again close with the 7,500 hour and 15,000 hour predictions being the closest (errors of 0.05 and $0.12 \%$, respectively), followed by 
the $10,000,5,000$ and 17,500 hour predictions (errors of $-0.27,-0.30$, and $0.39 \%$, respectively). No clear trends were evident in this analysis.

\section{Introduction}

Characterization of the thermomechanical properties of Thermal Ceramics' Min-K 1400TE material, hereafter referred to as Min-K, was undertaken at Oak Ridge National Laboratory (ORNL) in support of its use for structural applications under a gradient temperature regime in an inert environment. In particular, ORNL sought to determine the high temperature compressive strength and stress relaxation behavior of Min-K up to $900^{\circ} \mathrm{C}$ in helium along with the formulation of a general model for the mechanical behavior exhibited by Min-K under these conditions. Testing consisted of general high temperature compressive mechanical testing, isothermal stress relaxation testing, and stress relaxation testing of samples exposed to a thermal gradient. This report is an addendum to the previous final report issued for this project (ORNL/TM-2008/089) which covered the original three year project duration. This report presents data and results from the fourth and final year of the project which extended gradient stress relaxation testing out to two-year duration.

\section{Gradient Stress Relaxation Testing}

3.1 Experimental Procedures

Gradient stress relaxation testing was originally intended to be performed at various temperatures and loads as indicated in Table 1 (Gradient Sequence) using 6" $(15 \mathrm{~cm})$ diameter, 3" $(7.5 \mathrm{~cm})$ long cylindrical samples. Testing was performed using the set-up shown in Figure 1, which consists of an electromechanical testing machine (Instron Model 1380) equipped with load and displacement digital controllers, a $35 \mathrm{kN}$ load cell, a heated Inconel platen above the sample, and a single zone furnace. An aluminum environmental chamber with helium flow (99.999\% purity, flow rate of $70 \mathrm{~mm}$ ) was used for creating a controlled environment. Loading was performed under strain control utilizing a twelve-step loading scheme with loading every half hour at a rate of $5.56 \%$ strain/hour. Loading was followed by stress relaxation in strain control with testing carried out until the initial load was dissipated or had leveled off to a rate of change of less than $0.25 \mathrm{psi} /$ hour (1.7 $\mathrm{kPa} /$ hour) (up to 2000 hours).

Following completion of the initial isothermal and gradient stress relaxation testing, an effort was undertaken to convert two experimental set-ups for isothermal stress relaxation into set-ups for gradient stress relaxation and to improve the robustness of the gradient stress relaxation testing in an effort to complete tests of six-month to one-year duration. To facilitate this, the test frames were retrofitted with new heater platens, improved thermal insulation, improved electrical connections, and a back-up power supply system to run all four retrofitted test frames. The back-up power supply system (208 VAC, $3 \mathrm{PH}$, $4 \mathrm{~W}, 60 \mathrm{~Hz}, 111 \mathrm{~A}, 120$ cells) is shown in Figure 2.

Gradient stress relaxation testing was again performed using 6" $(15 \mathrm{~cm})$ diameter, 3" $(7.5$ $\mathrm{cm})$ long cylindrical samples. Temperature gradients for new testing consisted of $700 / 100^{\circ} \mathrm{C}$ (5 tests) and $800 / 190^{\circ} \mathrm{C}$ (1 test) with initial loads of $200 \mathrm{psi}(1380 \mathrm{kPa})$. A modified test procedure was implemented, based on the previous gradient stress 
relaxation test procedure and testing was performed using a set-up similar to that shown in Figure 1. This set-up consists of an electromechanical testing machine (Instron Model 1380) equipped with load and displacement digital controllers, a $35 \mathrm{kN}$ load cell, a heated Inconel platen above and below the sample, and a single zone furnace. An aluminum environmental chamber with helium flow (99.999\% purity, flow rate of $70 \mathrm{~mm}$ ) was used for creating a controlled environment.

Loading was performed under strain control utilizing a twelve-step loading scheme with loading every half hour at a rate of $5.56 \%$ strain/hour. Loading was followed by stress relaxation under constant strain with testing scheduled to be carried out for six-months (4,400 hours) and possibly extended to one-year (8,760 hours). Transient Strain Events (TSE) expected during actual material service were simulated using test specimens that had undergone stress relaxation testing in excess of 4,400 hours. These efforts involved four phases of testing. During Phase I of this testing, the strain was raised under displacement control to simulate shell cooling around the Min-K insulation material. The sample was held for approximately four days under fixed displacement. Then, Phase II was initiated by decreasing the strain under displacement control to simulate an expansion event. The sample was then held again under fixed displacement for thirty minutes. Phase III consisted of switching to load control and holding the existing stress level for one hour to collect data on the creep rate of the material given the post test stress level. Following the hold, the system was switched back to displacement control and Phase IV was started. For this phase, the strain was returned back to the original strain level prior to TSE testing. Following Phase IV, the test was put back under fixed displacement.

In parallel to the above long-term gradient stress relaxation testing, three additional tests were started with the intent of obtaining data of one-year duration (8,760 hours) under a variety of temperature gradients. Existing test frames were refurbished and retrofitted with modified heater platens, improved thermal insulation, improved electrical connections, and a back-up power supply system similar to that described above. Gradient stress relaxation testing was performed using 8" $(20 \mathrm{~cm})$ diameter, 1.856" (4 .7 $\mathrm{cm})$ thick right circular cylindrical samples. Temperature gradients for testing ranged from $1,100^{\circ} \mathrm{F}\left(593^{\circ} \mathrm{C}\right)$ down to room temperature with the gradients listed in Table 2 . All samples were subjected to an initial load of $7812 \mathrm{lbf}$ (155-158 psi, $1069-1089 \mathrm{kPa})$. A modified test procedure was written, based on previous gradient stress relaxation test procedures and testing was performed using a set-up similar to the one shown in Figure 1. A picture of a modified test frame used for this testing is shown in Figure 3.

Test frames were individually modified to accommodate physical attributes of the retrofitted frames. In general, this set-up consists of an electromechanical testing machine (rebuilt by Instrumet) equipped with load and displacement digital controllers run by MTS Test Works, a 10,000 lb. (44.5 kN) Sensotec Model 41 load cell, a heated metallic platen above and below the sample (304 stainless steel top, S-7 tool steel bottom), and an insulated refractory box surrounding the sample/heated platen assembly. An aluminum environmental chamber with helium flow $(99.999 \%$ purity, flow rate of $70 \mathrm{~mm}$ ) was used to create a controlled environment. Loading was performed in strain control at a rate of 
$0.4 \mathrm{~mm} /$ minute. Loading was followed by stress relaxation under constant strain with testing scheduled to be carried out for one-year (8,760 hours).

Additional test specimens for gradient testing were obtained and an effort was made to trace current and previous test specimens to specific batches supplied by Thermal Ceramics. An effort was also made to correlate specimen densities to specific test results. As far as could be determined, the corresponding sample densities, batch designations and test numbers are listed in Appendix 1.

\subsection{Results}

As discussed in the previous report (ORNL/TM-2008/089), initial gradient stress relaxation testing was completed under slightly different thermal conditions than those originally proposed $850 / 450^{\circ} \mathrm{C}$ and $450 / 190^{\circ} \mathrm{C}$ with a maximum initial stress of 100 and 200 psi $(690$, and $1380 \mathrm{kPa})$. The duration of these tests spanned between 100 and 1300 hours. The temperatures of the isothermal stress relaxation tests were selected under the assumption that the creep deformation of Min-K, and consequently, its stress-relaxation behavior up to $850^{\circ} \mathrm{C}$ is a thermally-activated process with a well-defined activation energy. The original temperatures for the gradient stress relaxation tests were selected to cover the entire temperature range explored in the isothermal testing. Actual test temperatures were dictated by the capabilities of the test system.

As also previously discussed in the previous report (ORNL/TM-2008/089), upon completion of the isothermal stress relaxation testing, two of the isothermal test configurations were converted to gradient test configurations and these frames were connected to the back-up power supply and testing was initiated on these frames. Results of this testing are documented in the previously issued report (ORNL/TM-2008/089). Of these tests, two were continued past the one-year mark. These were Gradient Test \#13 and $\# 15$, both with $700 / 100^{\circ} \mathrm{C}$ temperature gradients.

At the time of the writing of the previous report (ORNL/TM-2008/089), Test \#13 had been running for over one year with over 10,050 hours of exposure and a current level of 105 psi $(724 \mathrm{kPa})$. This test was continued during year four for a total test duration of 18,135 hours and a final stress level of 92 psi $(634 \mathrm{kPa})$. Because of malfunction of the machine cross-head, this test was simply terminated instead of being unloaded and cooled. Results for this test are shown in Figure 4.

Test \#15 was run unaltered from its start. At the time of the writing of the previous report (ORNL/TM-2008/089), this test had been running for over one year with over 9,735 hours of exposure and a current level of $126 \mathrm{psi}(869 \mathrm{kPa})$. The test was continued during year four to obtain data in excess of two years. Results for this test are shown in Figure 5. Total duration of this test was 17,935 hours and the final stress level was 120 psi (827 $\mathrm{kPa}$ ). Following completion of the test, TSE testing was performed on this sample. Phase I of the testing was successfully completed, raising the strain from $6.11 \%$ to $6.57 \%$ at a rate of $1.07 \%$ per hour and the stress from 120 to $146 \mathrm{psi}(827$ to $1,007 \mathrm{kPa})$. The sample was then held for approximately four days under fixed displacement and at the end of the 
fourth day the stress had relaxed to $145 \mathrm{psi}(1,000 \mathrm{kPa})$. Following this hold, Phase II was initiated by decreasing the strain from $6.57 \%$ to $5.95 \%$ at a rate of $1.52 \%$ per hour. This resulted in a loss of stress from approximately $145 \mathrm{psi}(1,000 \mathrm{kPa})$ to roughly $111 \mathrm{psi}$ $(765 \mathrm{kPa})$. The sample was then again held under fixed displacement for thirty minutes. Phase III consisted of switching to load control and holding the existing stress level for one hour. During this time, no measurable change in the strain level occurred. Following the hold, the system was switched back to displacement control and Phase IV was started. For this phase, the strain was returned from $5.95 \%$ back to the original strain level of $6.11 \%$. This resulted in a change of stress from approximately $111 \mathrm{psi}(765 \mathrm{kPa})$ to 120 psi $(827 \mathrm{kPa})$. Following Phase IV, the sample was held under fixed displacement for 18 hours. At the conclusion of testing the sample was at a stress level of $120 \mathrm{psi}(827 \mathrm{kPa})$. Following TSE testing, the sample was cooled to room temperature. Results from the TSE testing are shown in Figure 6.

The three additional stress relaxation tests run on the refurbished, modified mechanical test frames previously all reached one-year of test duration as described in the previous report (ORNL/TM-2008/089). The first test, which was started in April of 2006, had a gradient of $1,100 / 300^{\circ} \mathrm{F}$ and an initial loading of 7,812 lbf (155 psi). At the one-year mark (April 2007), this test had relaxed to $96 \mathrm{psi}(662 \mathrm{kPa})$. This test was continued until July of 2008 at which time it had been running for 19,650 hours and had reached a stress level of $84 \mathrm{psi}$. At the conclusion of the test, the sample was unloaded at a constant rate of $1.0 \%$ per hour until the current stress was reduced to $9.21 \mathrm{psi}(64 \mathrm{kPa})$, this corresponded to a reduction in strain from 11.44 to $8.92 \%$. Following the reduction in strain, the sample was held under constant displacement for 20.5 hours, during which the stress increased from 9.21 to $10.70 \mathrm{psi}(64$ to $74 \mathrm{kPa}$ ). The sample was then fully unloaded at the same constant rate of $1.0 \%$ per hour, followed by cooling of the sample. A plot of Test \#1 is shown in Figure 7.

The second test, which was also started in April of 2006, had a gradient of $1,000 / 160^{\circ} \mathrm{F}$ and an initial loading of 7,812 lbf (158 psi). At the one-year mark (April 2007), Test \#2 had relaxed to $115 \mathrm{psi}(793 \mathrm{kPa})$. This test was continued until April of 2008 when it was ended due to a computer failure. At the time of the failure, this test had been running for over 17,375 hours and was at a stress level of 100 psi $(689 \mathrm{kPa})$. A plot of Test \#2 is shown in Figure 8.

The third test, which was started in May 2006 , had a gradient of $900 / \approx 50^{\circ} \mathrm{F}$ and an initial loading of 7,812 lbf (157 psi). At the one-year mark (May 2007), Test \#3 had relaxed to $119 \mathrm{psi}(820 \mathrm{kPa})$. This test was continued until July of 2008 at which time it had been running for 18,455 hours and had reached a stress level of $116 \mathrm{psi}(800 \mathrm{kPa})$. At the conclusion of the test, the sample was unloaded at a constant rate of $1.0 \%$ per hour until half the current strain was removed (this corresponded to a reduction in strain from approximately 3.6 to $1.8 \%)$. This resulted in a reduction of stress to $45.37 \mathrm{psi}(313 \mathrm{kPa})$. Following the reduction in strain, the sample was held under constant displacement for 19.5 hours during which time the stress increased from 45.37 to 46.62 psi (313 to 321 $\mathrm{kPa}$ ). The sample was then fully unloaded at the same constant rate of $1.0 \%$ per hour, followed by cooling of the sample. A plot of Test \#3 is shown in Figure 9. 


\section{Modeling}

The previous report (ORNL/TM-2008/089) described the applicability of an Arrhenius type model to describe the isothermal stress-relaxation of Min-K and the extension of this model to analyze the stress-relaxation behavior of a Min-K component subjected to a constant axial strain under a temperature gradient through the discretization of a sample into isothermal sections with the stressrelaxation of each section being described using the isothermal model. Also, the concept of developing a closed-form solution was discussed, along with using finiteelement methods to describe the stress-relaxation of the Min-K component based on collected isothermal data. Additionally, data from isothermal stress relaxation testing performed at temperatures between 850 and $190^{\circ} \mathrm{C}$ was incorporated into the finite element program ANSYS to model the relaxation behavior of Min-K. After the applicability of the creep model was verified for the isothermal case at different temperatures, the model was used to analyze the case when a temperature gradient is applied to the test specimen.

For the long term gradient stress relaxation testing, a log-log model was fitted to the data and to previous predictions made using isothermal stress relaxation data as data became available. Data was also fit to the previously derived ORNL mathematical model, a Maxwell model, and a KWW model. Subsequent modeling with data in excess of oneyear duration was also pursued. From this initial analysis, it was found that a simple log function $(\mathrm{y}=\mathrm{a}-\mathrm{b} * \log (\mathrm{x}))$ was sufficient to fit this long-term gradient stress relaxation data as shown in Figure 10 for Test \#13 and Test \#15. In both cases, an R value of 0.98 was obtained using this function. After obtaining two-year duration data, the same log function was used to fit the data for Test \#13 and Test \#15 as shown in Figure 11. In both cases, an $\mathrm{R}$ value of greater than 0.97 was obtained using this function.

Also, the effect of fitting various time scales of data for predicting long term behavior was investigated. As reported in the previous report (ORNL/TM-2008/089) fits were made using the same simple log function as above using data from 1,000, 2,500, 5,000, 7,500, and 9,000 hours. In each case, predictions were made out to 10,000 and 50,000 hours as shown in Figure 12 and Figure 13, respectively. From this analysis, it appeared that data between 5,000 and 7,500 hours was sufficient to predict behavior out to 10,000 hours. Data of less than 5,000 hours tended to under predict the stress relaxation. Data of greater than 7,500 hours accurately predicted the stress relaxation, but did not provide any improvement in the prediction. Therefore, assuming that the process responsible for the creep/stress relaxation behavior exhibited was smooth and continuous; it was hypothesized that it may not be necessary to extend testing to this duration, even for predictions out to 50,000 hours.

A similar investigation of the effect of fitting various time scales of data for predicting long term behavior was repeated with the two-year duration data. Fits were made using the same simple log function as above and data from 1,000, 2,500, 5,000, 7,500, 10,000, $12,500,15,000$, and 17,500 hours. Predictions out to 17,500 and 50,000 hours for Test $\# 13$ and Test \#15 are shown in Figure 14 and Figure 15, respectively. Analysis incorporating the new data out to 17,500 hours found that at 10,000 hours the predictions 
of the 7,500 and 12,500 hour fits were the best. For Test \#13, no increase in accuracy was seen for the 15,000 hour fit and a decrease in accuracy was seen for the 17,500 hour fit. For Test \#15, fits of data less than 7,500 hours tended to under predict the stress and fits of data greater than 12,500 hours tended to over predict the stress.

The same kind of analysis as reported in the previous report (ORNL/TM-2008/089) was repeated with data at 17,500 hours. For Test \#13, all predictions over estimated the remaining stress in the sample with the 15,000 and 17,500 hour predictions being the closest (errors of 4.69 and 6.25\%, respectively), followed by the 5,000 and 2,500 hour predictions (errors of 6.70 and $6.92 \%$, respectively). The predictions for Test \#15 where found to be much better. Predictions made with 5,000 hours of data or less under predicted the remaining stress and predictions made with 7,500 hours of data or more over predicted the remaining stress. The 12,500 hour prediction was the closest with an error of $0.52 \%$, closely followed by the predictions with 7,000 and 10,000 hours of data (errors of 0.54 and $0.62 \%$, respectively).

Mathematical modeling of the Min-K stress relaxation behavior exhibited by the additional long-term gradient stress relaxation testing under a variety of temperature gradients was also performed. The same simple $\log$ function $(\mathrm{y}=\mathrm{a}-\mathrm{b} * \log (\mathrm{x}))$ utilized above was used to fit the long-term gradient stress relaxation data obtained. Fits for each test are shown in Figure 16. In each case, an $\mathrm{R}$ value of 0.90 or greater was obtained using this function.

Similarly an investigation of the effect of fitting various time scales of data for predicting long-term behavior was performed. Fits were made using the same simple log function as above using data from 1,000, 2,500, 5,000, 7,500, 10,000, 12,500, 15,000, and 17,500 hours, where possible. Predictions out to 17,500 and 50,000 hours for Test \#1, Test \#2 and Test \#3 are shown in Figure 17, Figure 18, and Figure 19, respectively. Analysis of the above data out to 17,500 hours (out to 12,500 hours for Test \#2) was carried out to determine the accuracy of the various fits to predict actual test data. For Test \#1, all predictions over estimated the remaining stress in the sample with the 5,000 and 7,500 hour predictions being the closest (errors of 4.89 and $5.17 \%$, respectively), followed by the 17,500, 10,000 and 12,500 hour predictions (errors of 5.28, 5.51, and 5.54\%, respectively). For Test \#2, all predictions were very close, but the prediction made with 12,500 hours of data was the closest (error of $0.02 \%$ ), followed by predictions made with 10,000 hour and 1,000 hour data (errors of -0.16 and $0.32 \%$, respectively). For Test \#3, predictions were again close with the 7,500 hour and 15,000 hour predictions being the closest (errors of 0.05 and $0.12 \%$, respectively), followed by the 10,000, 5,000 and 17,500 hour predictions (errors of $-0.27,-0.30$, and $0.39 \%$, respectively). No clear trends were evident in this analysis.

Finally, a study was performed to analyze how the coefficients ( $a$ and b) of the log-log model change as the data duration used for the analysis increases. For this analysis, data and curve fits from original long-term gradient stress relaxation Test \#15 was used, along with data and curve fits from the additional long-term stress relaxation Test \#1 and \#2. Plots of the change in coefficient values verses the duration of data used for the curve fit 
are shown in Figure 20 for each test, respectively. For Test \#15 coefficient values fluctuate for the low time duration fits $(1,000,2,500$, and 5,000 hour), but then settle to a relatively stable value for fits of duration of 7,500 hours or greater. For Test \#1 the coefficient values appear to increase as the duration of time used for the fit is increased and then level off to a stable value for fits of duration of 10,000 hours or greater. For Test \#2 the coefficient values were found to fluctuate for the low time duration fits $(1,000$, $2,500,5,000$, and 7,500 hour), but then level off to a stable value for fits of duration of 12,500 hours or greater.

\section{Lessons Learned}

- Methods of platen construction were refined through the project to produce heated platens capable of $900^{\circ} \mathrm{C}$ and continuous operation in excess of two year (17,520 hour) duration. Final platen construction utilized Inconel and various steels for the platen body, dependent on temperatures, and nichrome resistive heaters encased in ceramic insulation ${ }^{3}$.

- For long-term testing, such as that undertaken in this project, a back-up power supply system should be utilized.

- The original assumption that there is no radial dependence on temperature in the gradient temperature test samples and that temperature only changes linearly along the height of the specimen was found to be false leading to adjustments being needed for application of the ANSYS model. It was found that the axial temperature gradient is uniform at the center of the specimen, but temperatures away from the center of the test specimen approach the internal temperature of the furnace or surrounding insulation.

- Data from testing were fitted throughout the test lives with the derived ORNL mathematical model, a Maxwell model, and a KWW model. Subsequent modeling with data in excess of one-year and two-year duration was also pursued. It was found that a simple $\log$ function $(\mathrm{y}=\mathrm{a}-\mathrm{b} * \log (\mathrm{x}))$ best describes the long-term temperature gradient stress relaxation data.

- Initial fits of the gradient test data were made using a same simple log function and data from 1,000, 2,500, 5,000, 7,500, and 9,000 hours. In each case, predictions were made out to 10,000 and 50,000 hours. From this analysis, it appeared that data between 5,000 and 7,500 hours was sufficient to predict behavior out to 10,000 hours. Data of less than 5,000 hours tended to under predict the stress relaxation. Data of greater than 7,500 hours accurately predicted the stress relaxation, but did not provide any improvement in the prediction. Therefore it was initially hypothesized that it may not be necessary to extend testing to this duration, even for predictions out to 50,000 hours. Subsequent analysis was performed with data out to 17,500 hours. For Test $\# 13$, all predictions over estimated the remaining stress in the sample with the 15,000 and 17,500 hour predictions being the closest (errors of 4.69 and $6.25 \%$, respectively), followed by the 5,000 and 2,500 hour predictions (errors of 6.70 and $6.92 \%$, respectively). The predictions for Test \#15 were found to be much better. Predictions made with 5,000 hours of data or less under predicted the remaining stress and predictions made with 7,500 hours of data or more over predicted the remaining stress.

\footnotetext{
${ }^{3}$ International Ceramics \& Heating Systems, Inc., Circleville, New York
} 
The 12,500 hour prediction was the closest with an error of $0.52 \%$, closely followed by the predictions with 7,000 and 10,000 hours of data (errors of 0.54 and $0.62 \%$, respectively).

- For the additional long-term temperature gradient stress relaxation testing under a variety of temperature gradients fits were made using the same simple log function as above using data from 1,000, 2,500, 5,000, 7,500, 10,000, 12,500, 15,000, and 17,500 hours, where possible. Analysis of the above data out to 17,500 hours (out to 12,500 hours for Test \#2) was carried out to determine the accuracy of the various fits to predict actual test data. For Test $\# 1$, all predictions over estimated the remaining stress in the sample with the 5,000 and 7,500 hour predictions being the closest (errors of 4.89 and $5.17 \%$, respectively), followed by the 17,500, 10,000 and 12,500 hour predictions (errors of 5.28, 5.51, and 5.54\%, respectively). For Test \#2, all predictions were very close, but the prediction made with 12,500 hours of data was the closest (error of $0.02 \%$ ), followed by predictions made with 10,000 hour and 1,000 hour data (errors of -0.16 and $0.32 \%$, respectively). For Test \#3, predictions were again close with the 7,500 hour and 15,000 hour predictions being the closest (errors of 0.05 and $0.12 \%$, respectively), followed by the 10,000, 5,000 and 17,500 hour predictions (errors of $-0.27,-0.30$, and $0.39 \%$, respectively). No clear trends were evident in this analysis.

- A study to analyze how the coefficients ( $a$ and $b$ ) of the log-log model change as the data duration used for the analysis increases showed that in general coefficient values tend to fluctuate for the low time duration fits (1,000 to 7,500 hour), but then settle to a relatively stable value for the longer time duration fits in excess of 10,000 hours.

6. Acknowledgements

The authors acknowledge the work of ORNL Technical Interns Andre Prigmore and Zachary Burns who contributed to the maintaining of the long-term testing. Continued technical advisement and input was provided by Al Lewis and Nora Low (United Technologies) and Dave Svrjcek (Teledyne Energy Systems, Inc.). The authors would also like to thank Jy-An John Wang for reviewing the manuscript. 
Tables and Figures

Table 1. Stress Relaxation Test Matrix

(note: $100 \mathrm{psi}=690 \mathrm{kPa}, 200 \mathrm{psi}=1380 \mathrm{kPa}$ )

\begin{tabular}{|c|c|c|c|c|}
\hline \multicolumn{4}{|c}{ Temp Profile @ 50psi } & \multicolumn{2}{c|}{ Temp Profile @ 200psi } \\
\hline Temp C & $\begin{array}{c}\text { Gradient } \\
\text { Sequence }\end{array}$ & $\begin{array}{c}\text { Soaked } \\
\text { Sequence }\end{array}$ & $\begin{array}{c}\text { Gradient } \\
\text { Sequence }\end{array}$ & $\begin{array}{c}\text { Soaked } \\
\text { Sequence }\end{array}$ \\
\hline 190 & $4(450 * / 190 C)$ & 12,16 & $2(450 * / 190)$ & 10,15 \\
\hline 382 & - & 11,14 & - & 9,13 \\
\hline 813 & - & 7,8 & - & 5,6 \\
\hline 850 & $3(850 / 450 *)$ & 3,4 & $1(850 / 450 *)$ & 1,2 \\
\hline
\end{tabular}

Table 2. Additional Long-Term Gradient Stress Relaxation Testing Matrix

\begin{tabular}{|c|c|c|}
\hline Hot Side Temperature & Cold Side Temperature & Initial Load \\
\hline $900^{\circ} \mathrm{F}\left(482^{\circ} \mathrm{C}\right)$ & $\mathrm{RT}$ & $7,812 \mathrm{lbf}(1069 \mathrm{kPa})$ \\
\hline $1,000^{\circ} \mathrm{F}\left(538^{\circ} \mathrm{C}\right)$ & $160^{\circ} \mathrm{F}\left(71^{\circ} \mathrm{C}\right)$ & $7,812 \mathrm{lbf}(1089 \mathrm{kPa})$ \\
\hline $1,100^{\circ} \mathrm{F}\left(593^{\circ} \mathrm{C}\right)$ & $300^{\circ} \mathrm{F}\left(149^{\circ} \mathrm{C}\right)$ & $7,812 \mathrm{lbf}(1082 \mathrm{kPa})$ \\
\hline
\end{tabular}

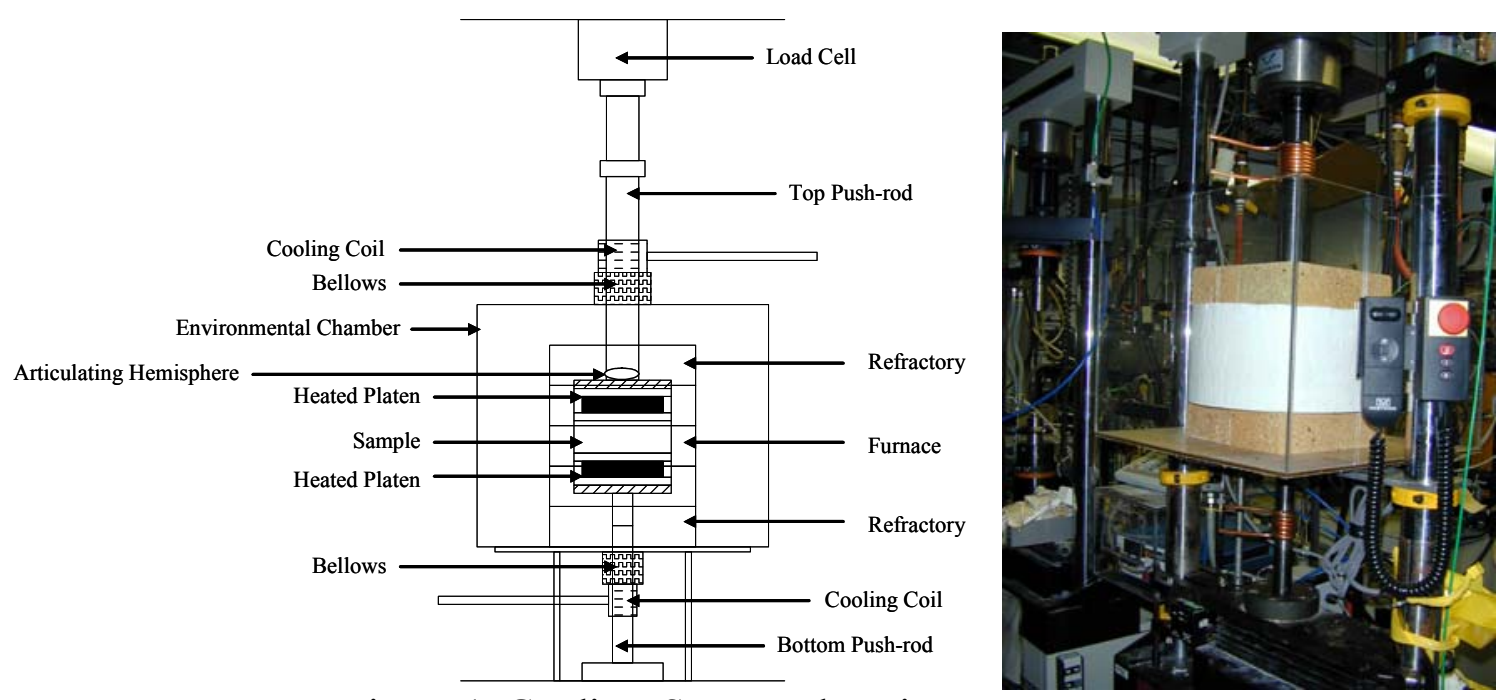

Figure 1. Gradient Stress Relaxation Test Frame 


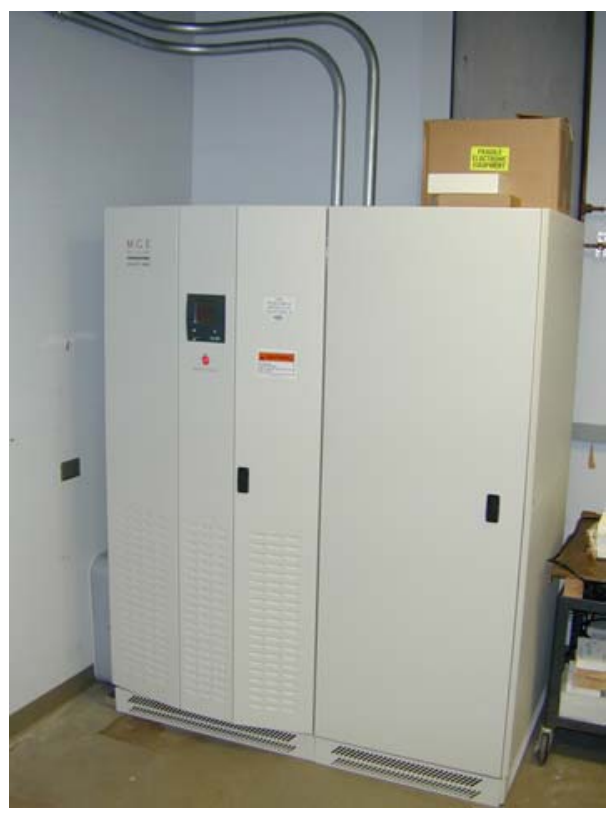

Figure 2. Installed Back-Up Power Supply System for Gradient Test Systems

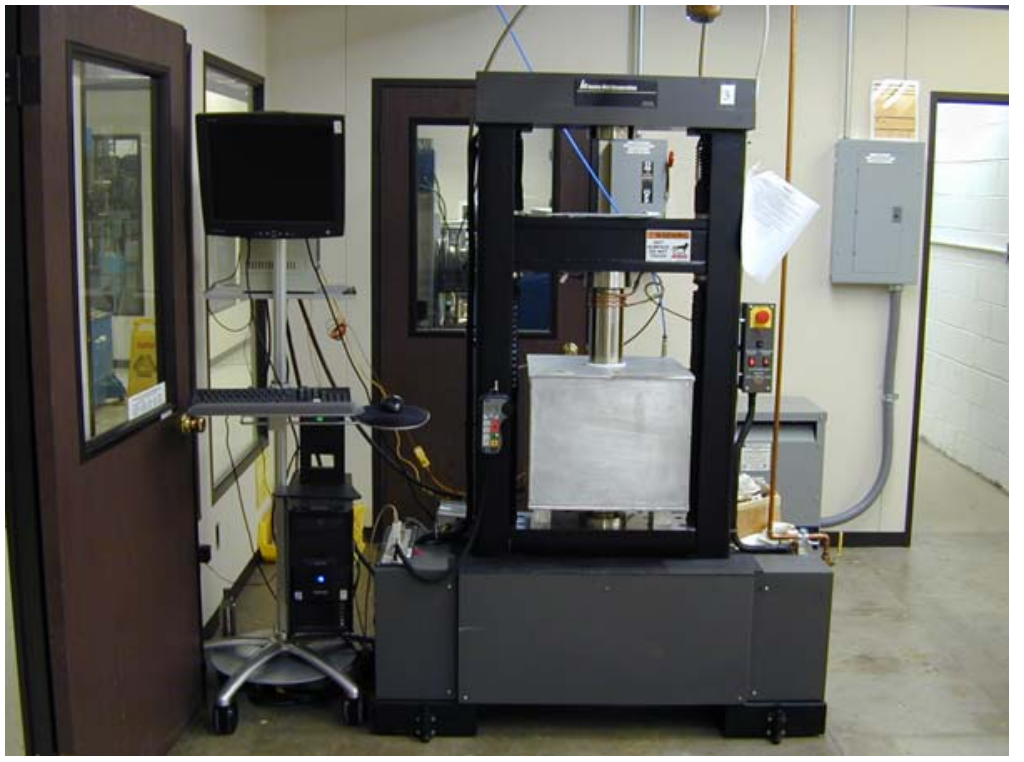

Figure 3. Picture of Modified Gradient Stress Relaxation Test Frame 
Gradient Test \#13

$\left(700 / 100^{\circ} \mathrm{C}, 200 \mathrm{psi}\right)$

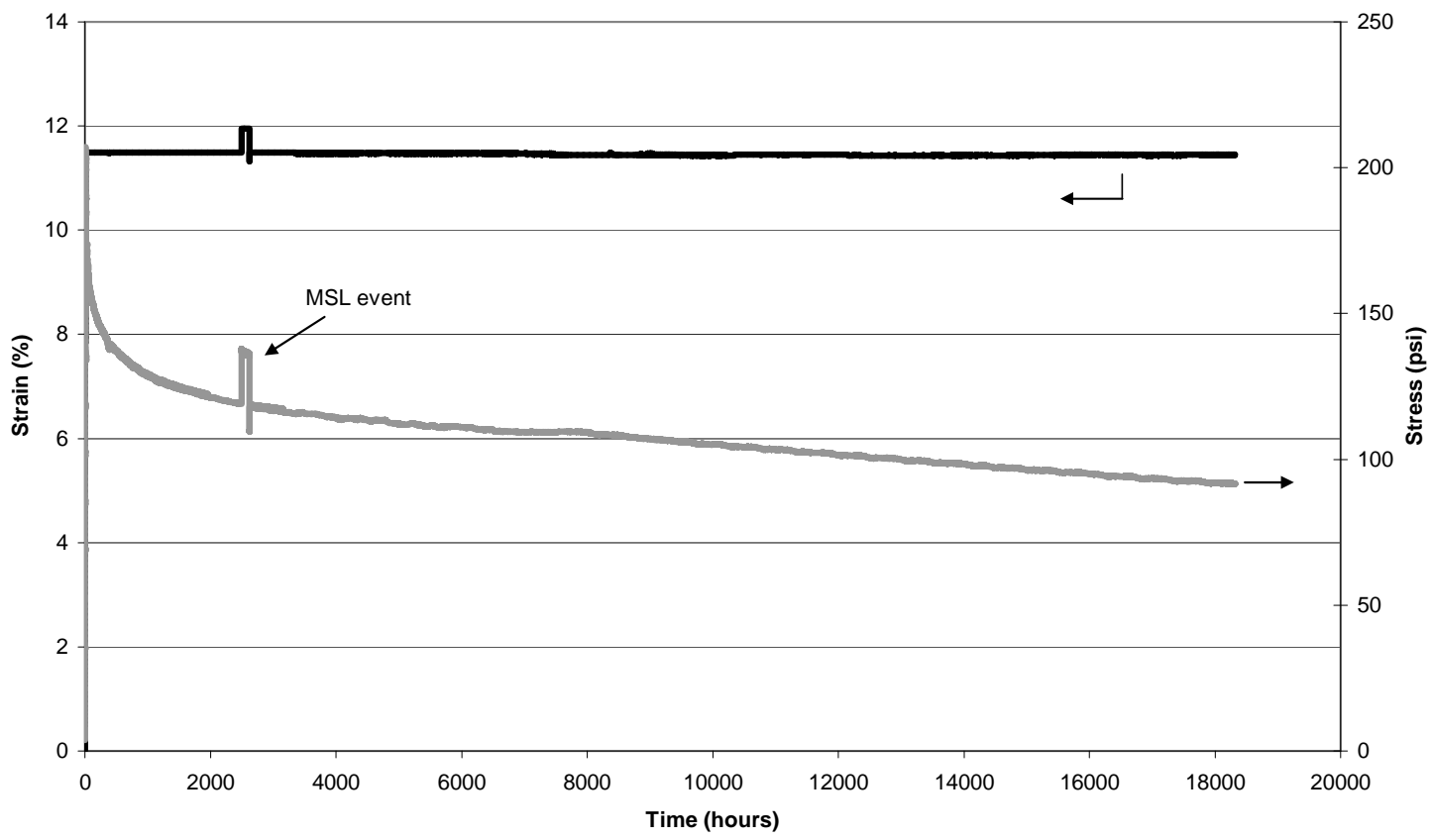

Figure 4. Results from $700 / 100^{\circ} \mathrm{C}$ Gradient Stress Relaxation Test (Test \#13)

Gradient Test \#15

$\left(700 / 100^{\circ} \mathrm{C}, 200 \mathrm{psi}\right)$

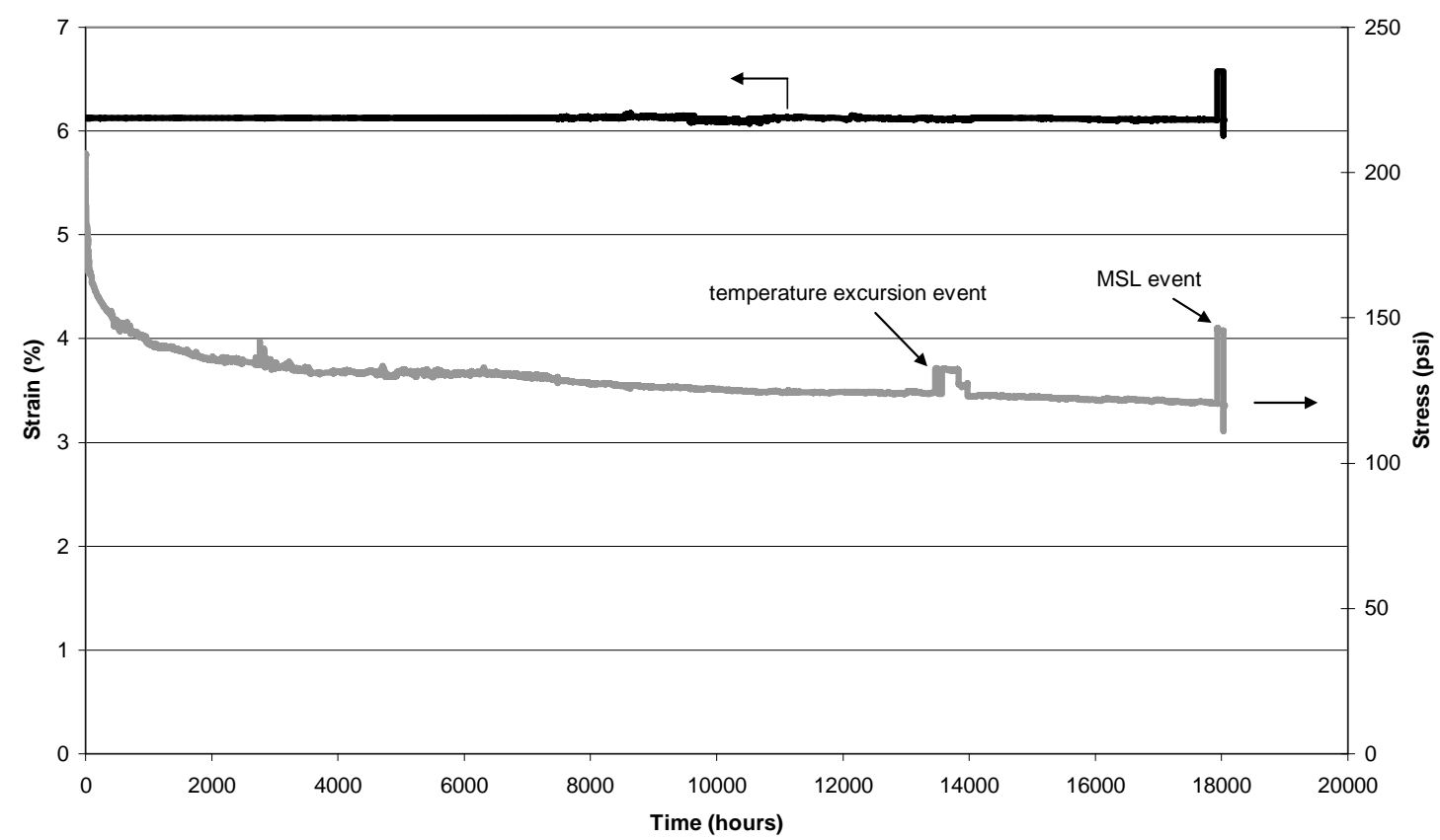

Figure 5. Results from $700 / 100^{\circ} \mathrm{C}$ Gradient Stress Relaxation Test (Test \#15) 


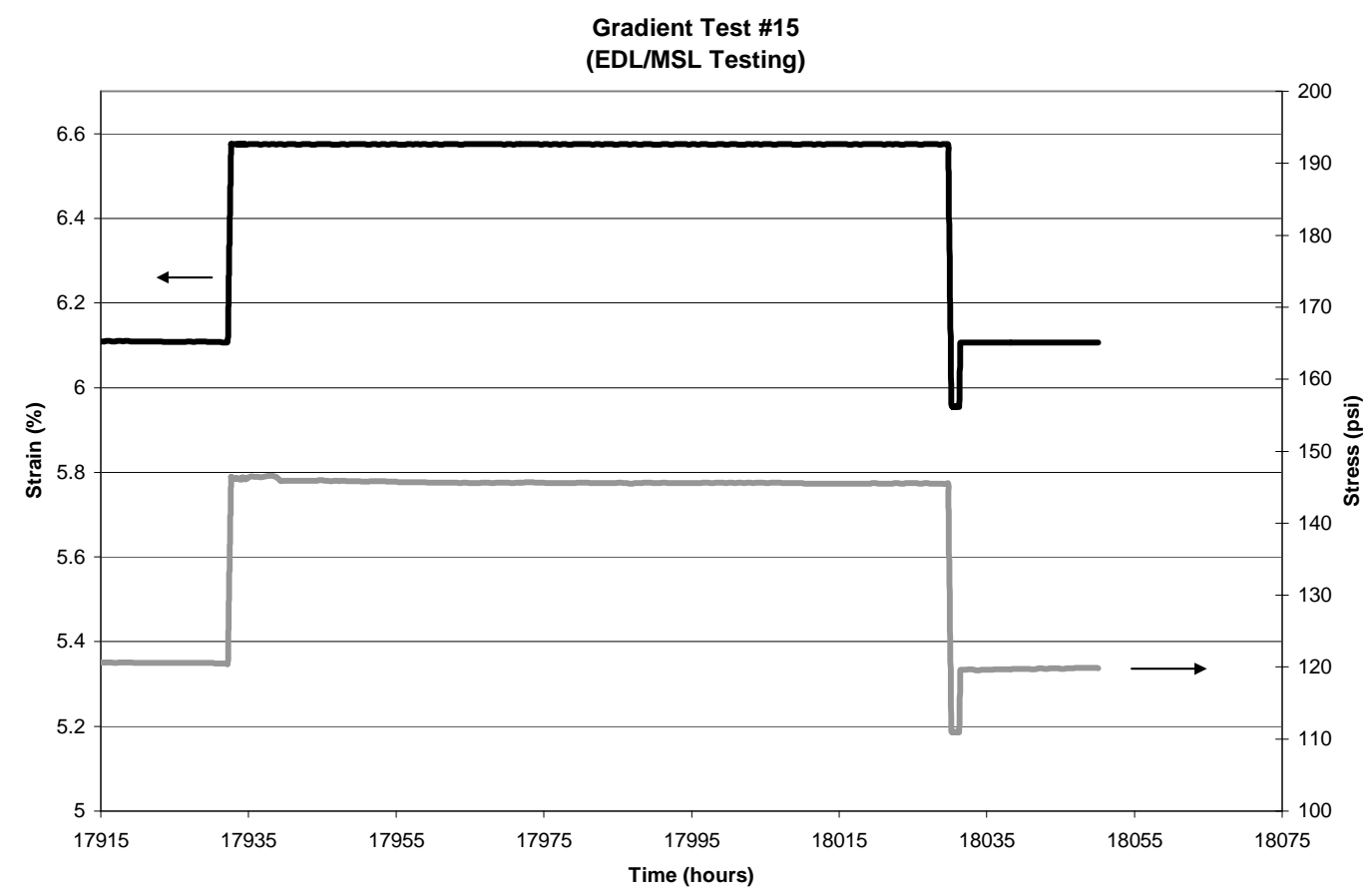

Figure 6. Results from $700 / 100^{\circ} \mathrm{C}$ Gradient Stress Relaxation Test (Test \#15) TSE Testing

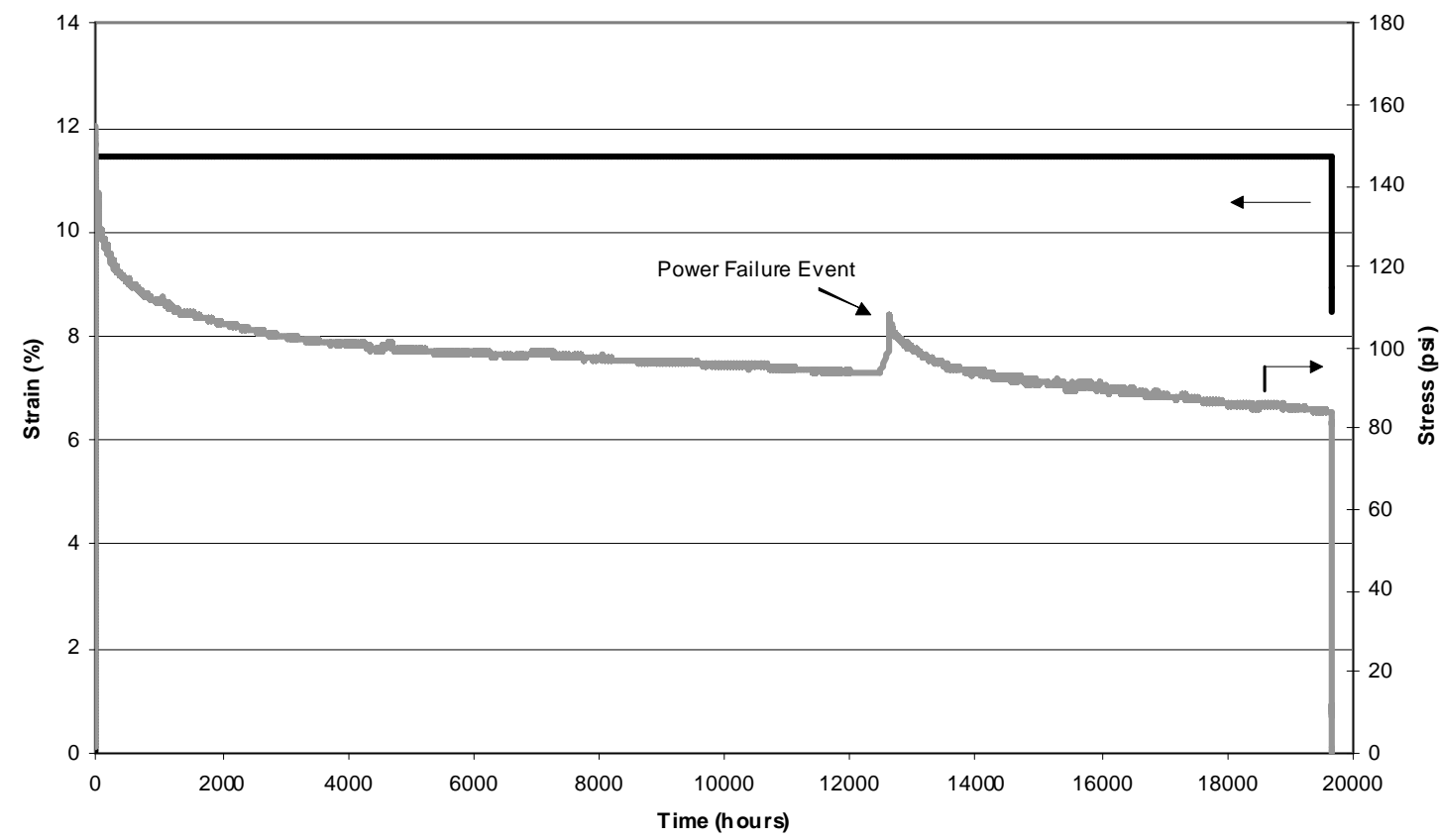

Figure 7. Results from $1,100 / 300^{\circ} \mathrm{F}$ Gradient Stress Relaxation Test 


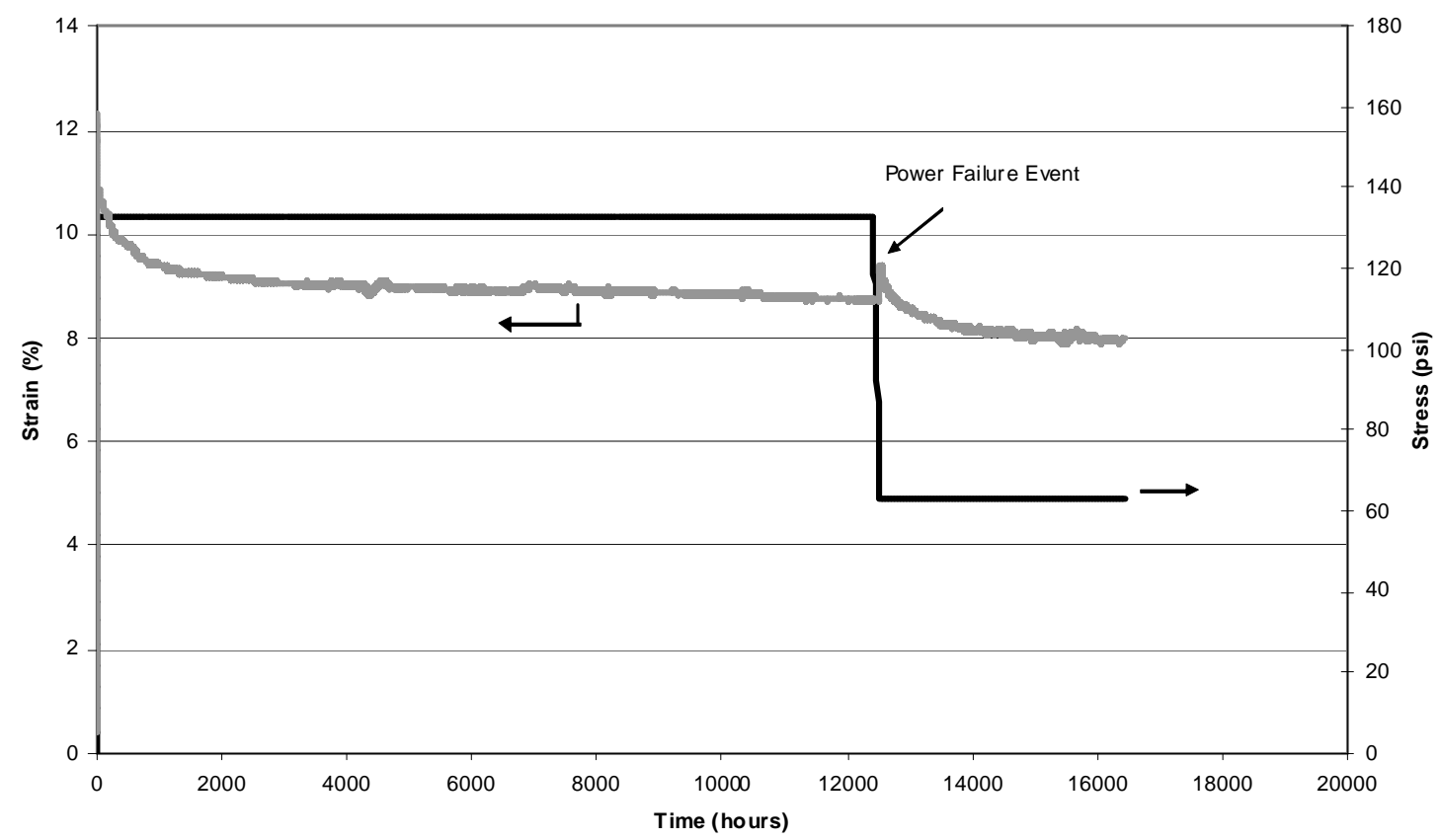

Figure 8. Results from $1,000 / 160^{\circ} \mathrm{F}$ Gradient Stress Relaxation Test

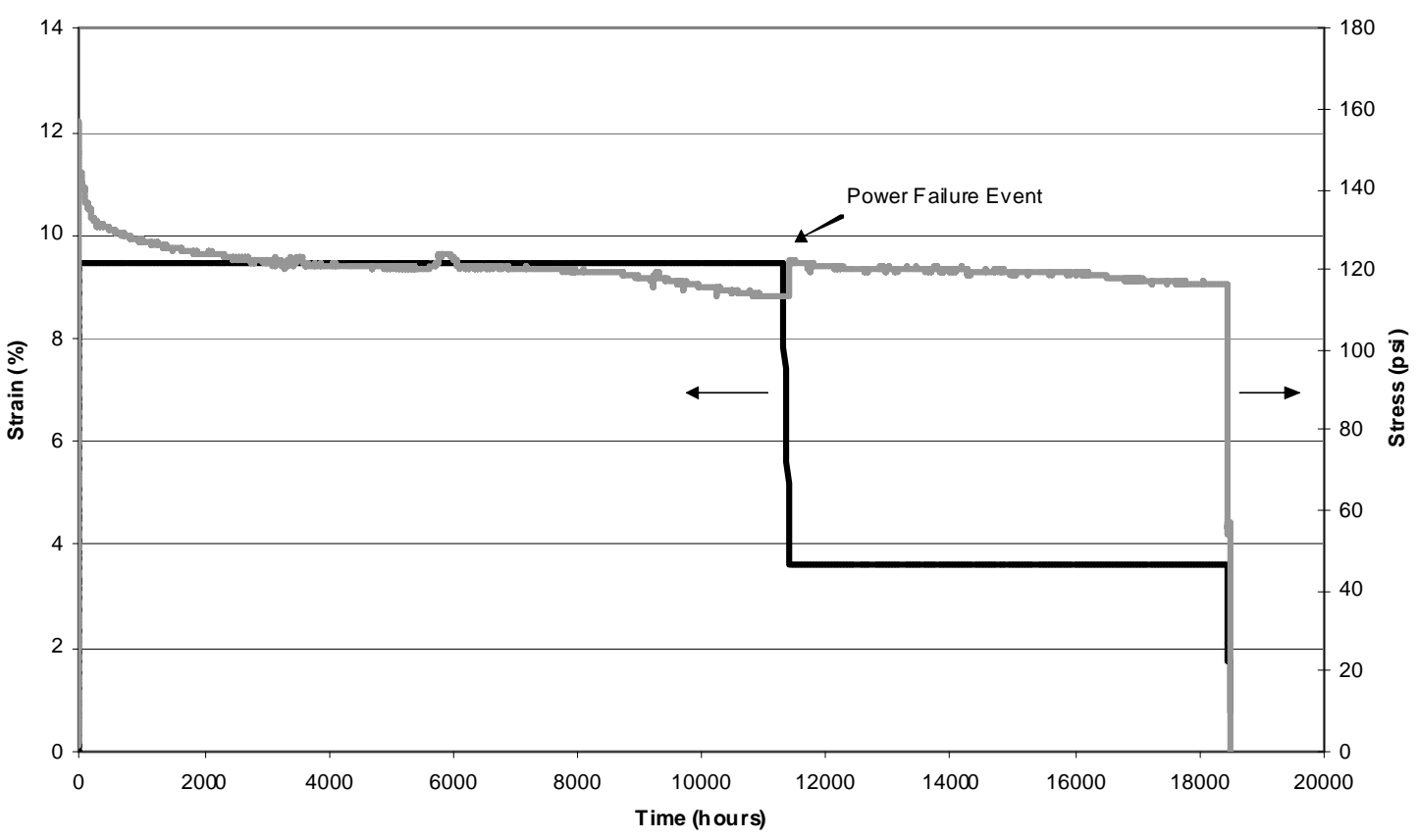

Figure 9. Results from $900^{\circ} \mathrm{F}-\left(\approx 50^{\circ} \mathrm{F}\right)$ Gradient Stress Relaxation Test 


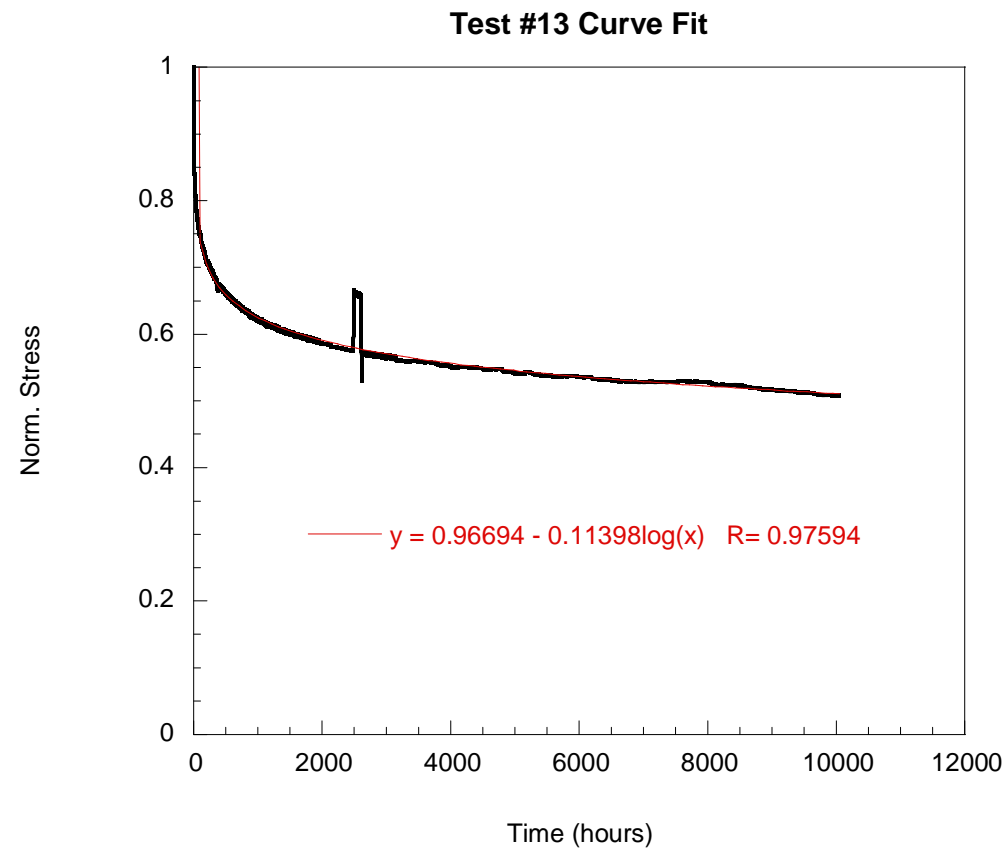

a)

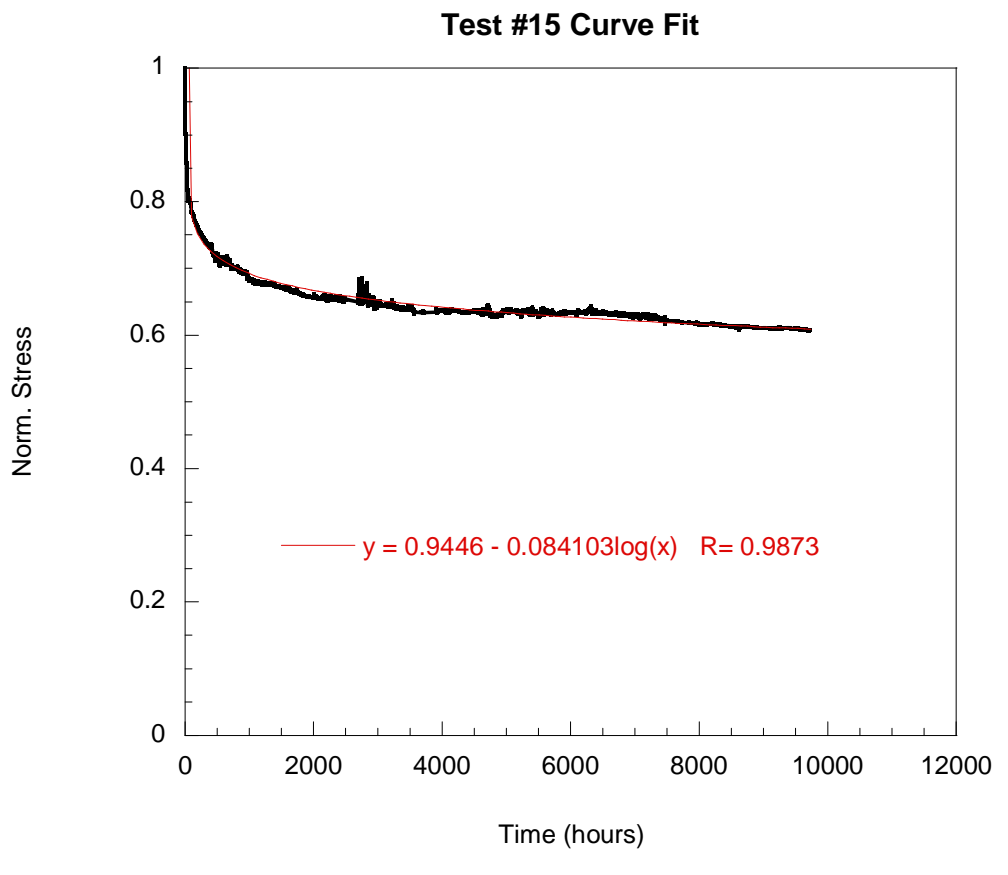

b)

Figure 10. Log Function Curve Fits of One-Year Long-Term Gradient Stress Relaxation Data

(a - Test \#13, b - Test \#15) 


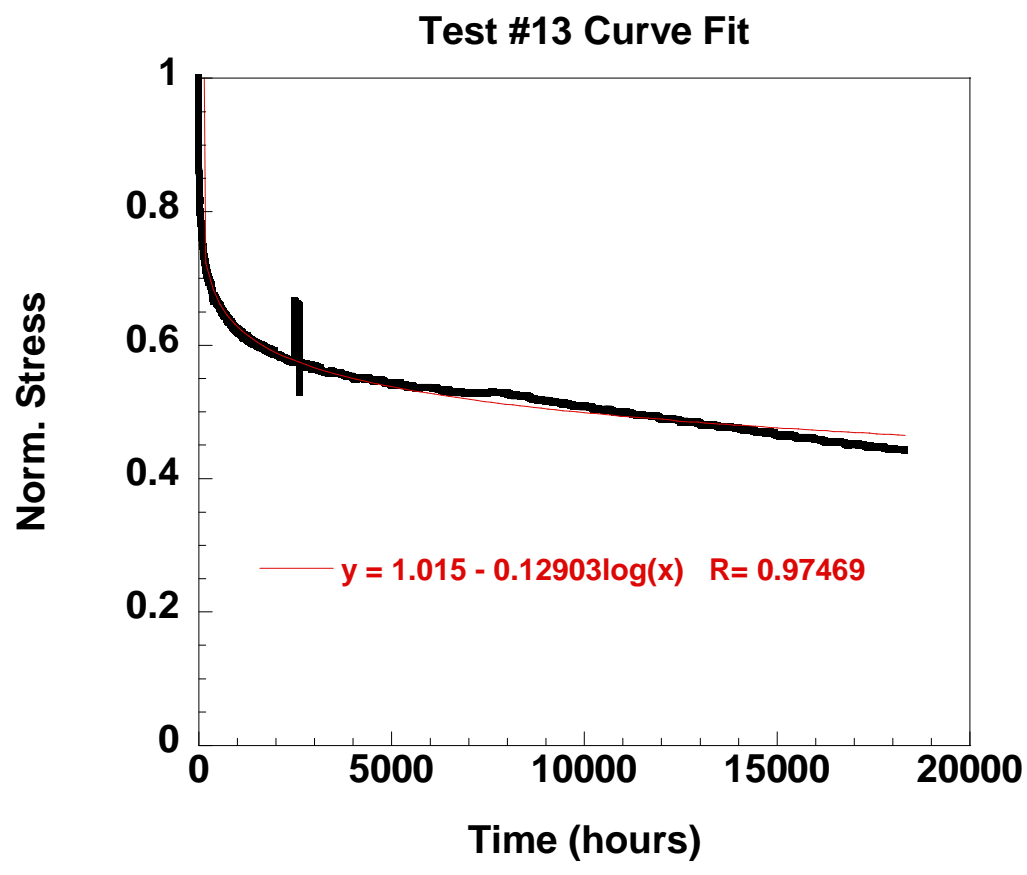

a)

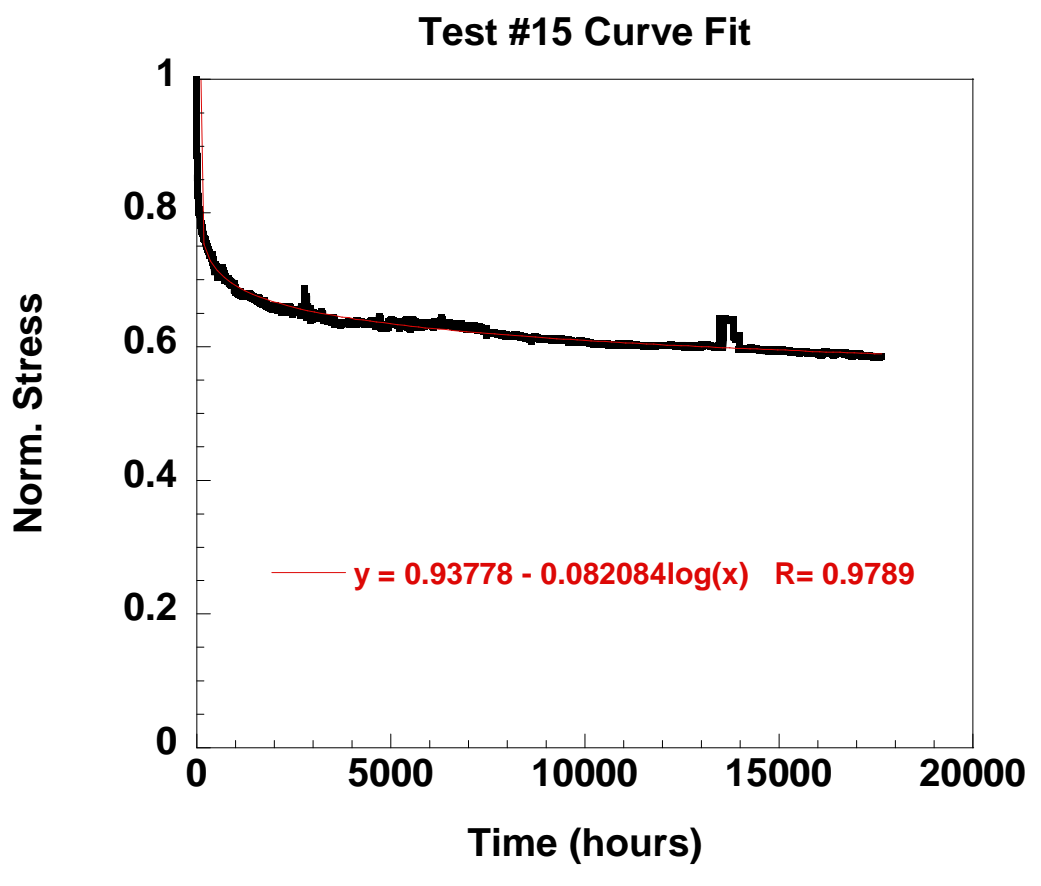

Figure 11. Log Function Curve Fits of Two-Year Long-Term Gradient Stress Relaxation Data

(a - Test \#13, b - Test \#15) 
Test \#13 Curve Fits

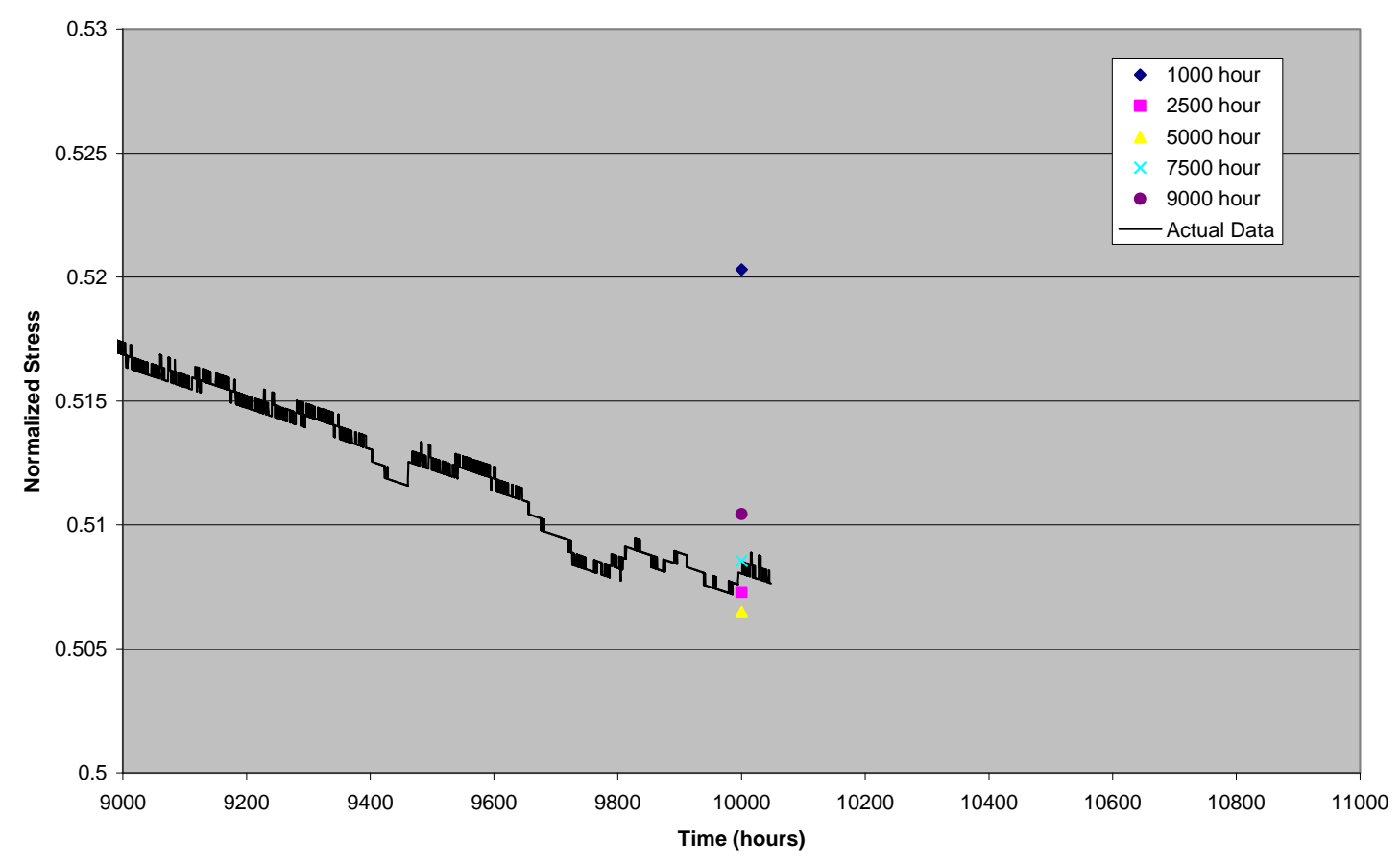

Test \#13 Curve Fits

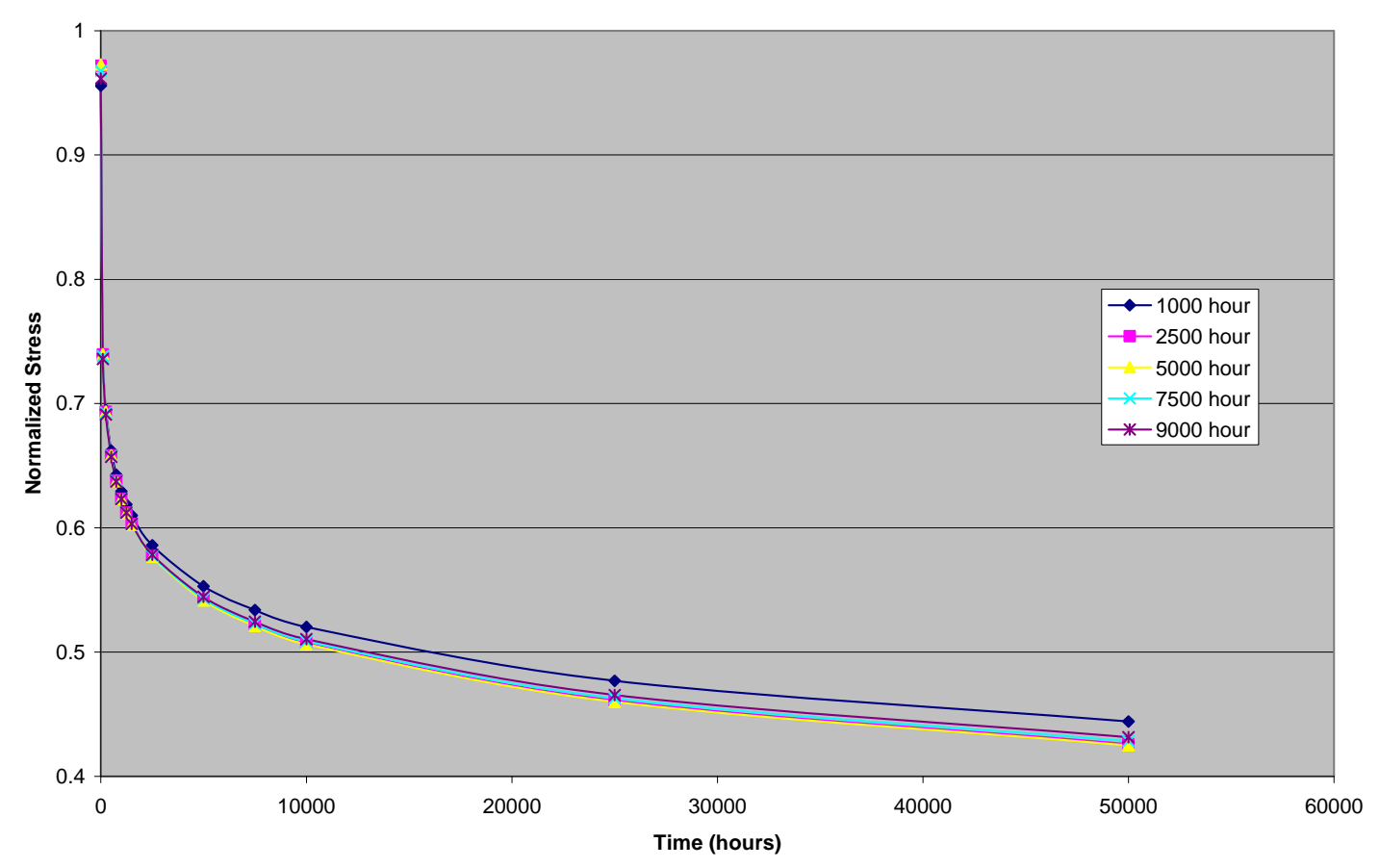

Figure 12. Gradient Test \#13 Log Fit Predictions (year three) 
Test \#15 Curve Fits

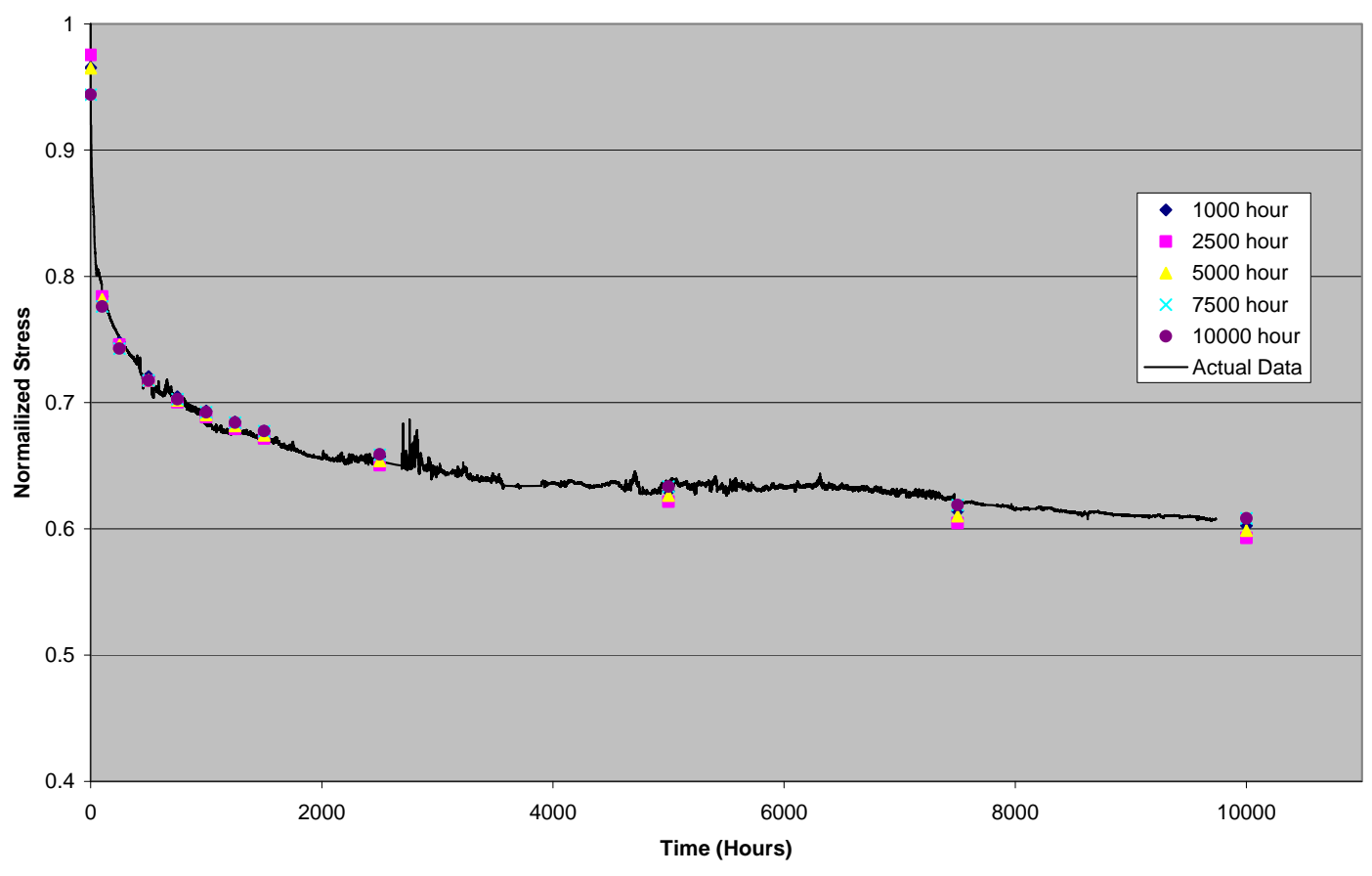

Test \#15 Curve Fits

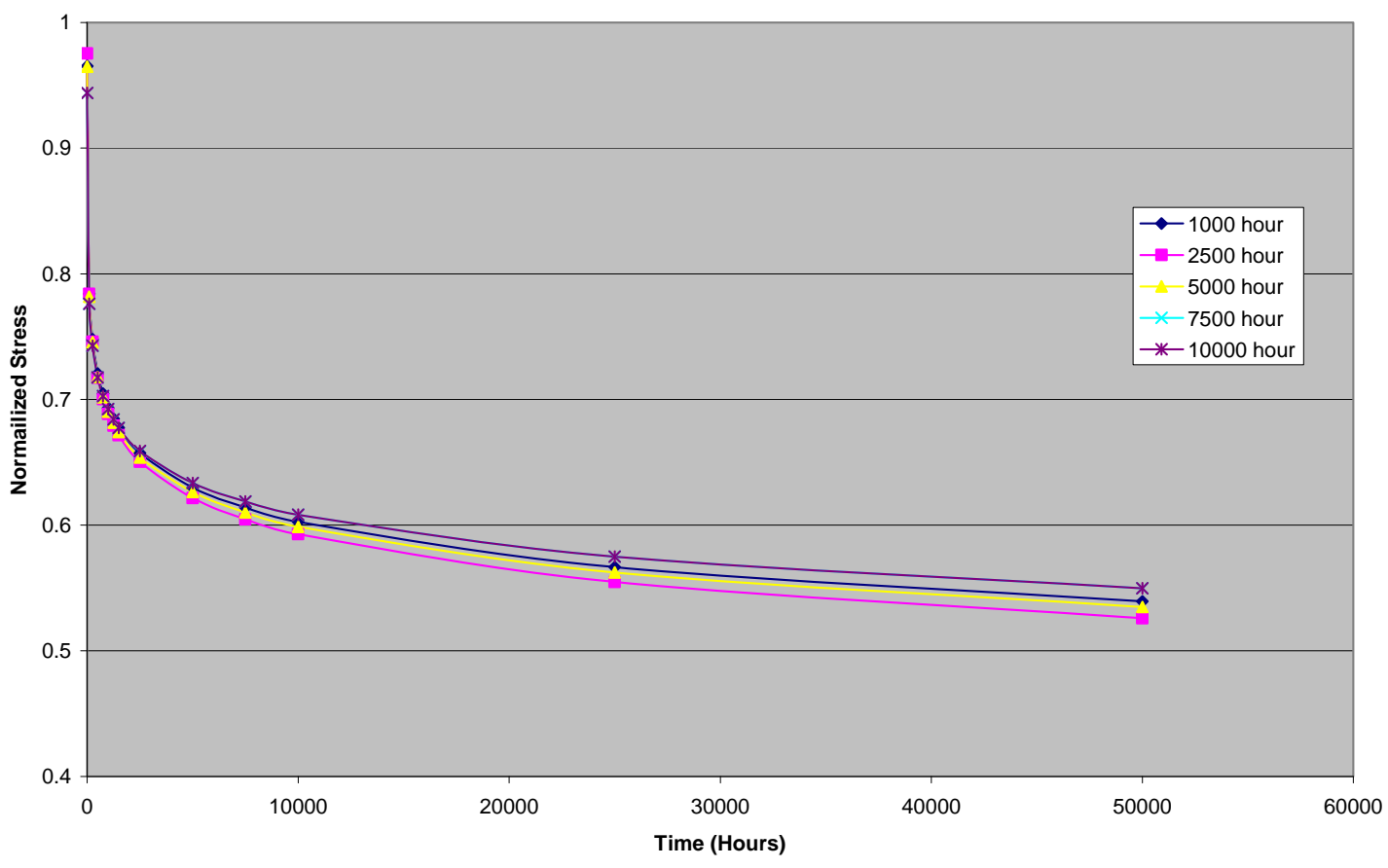

Figure 13. Gradient Test \#15 Log Fit Predictions (year three) 
Test \#13 Curve Fits

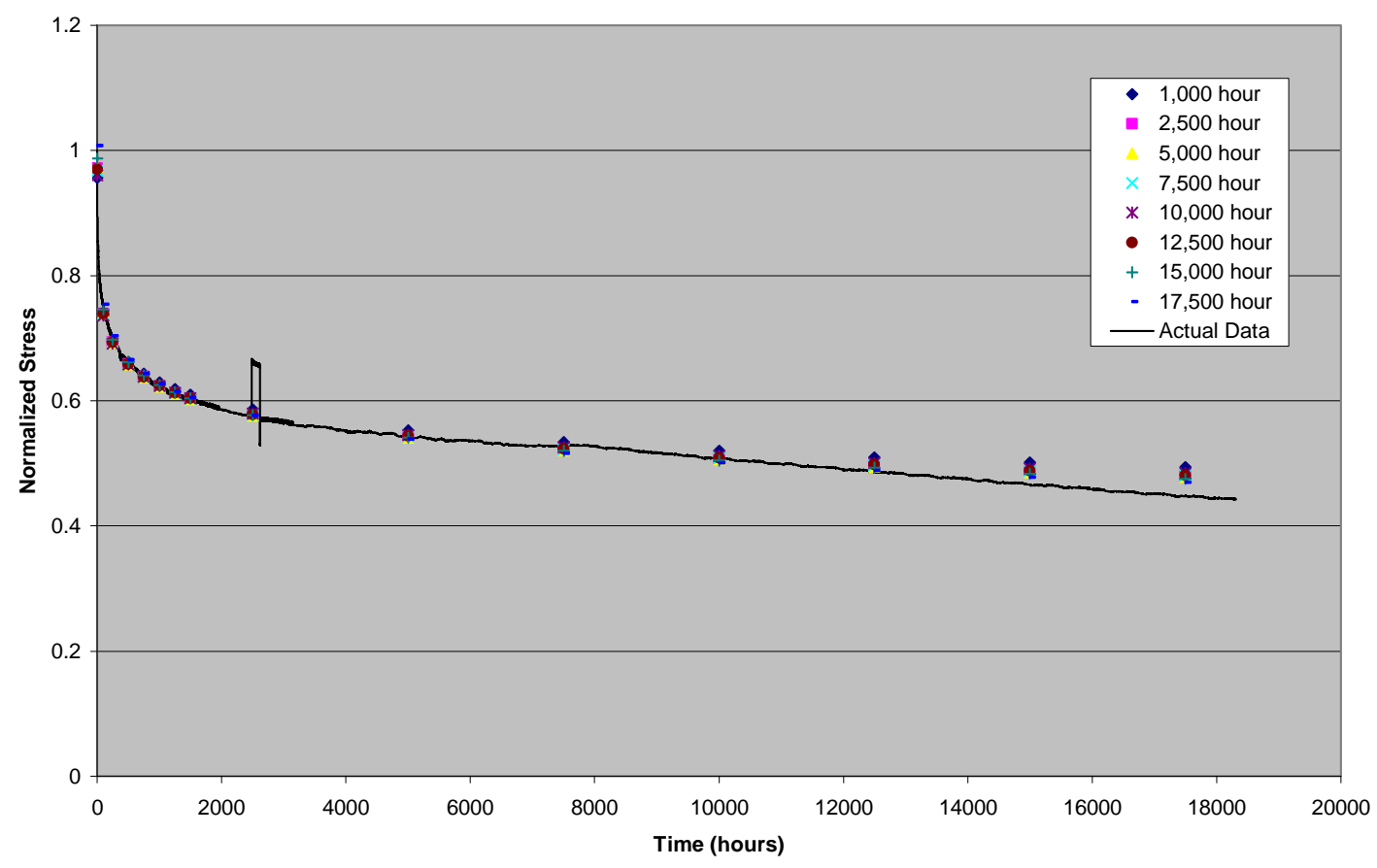

Test \#13 Curve Fits

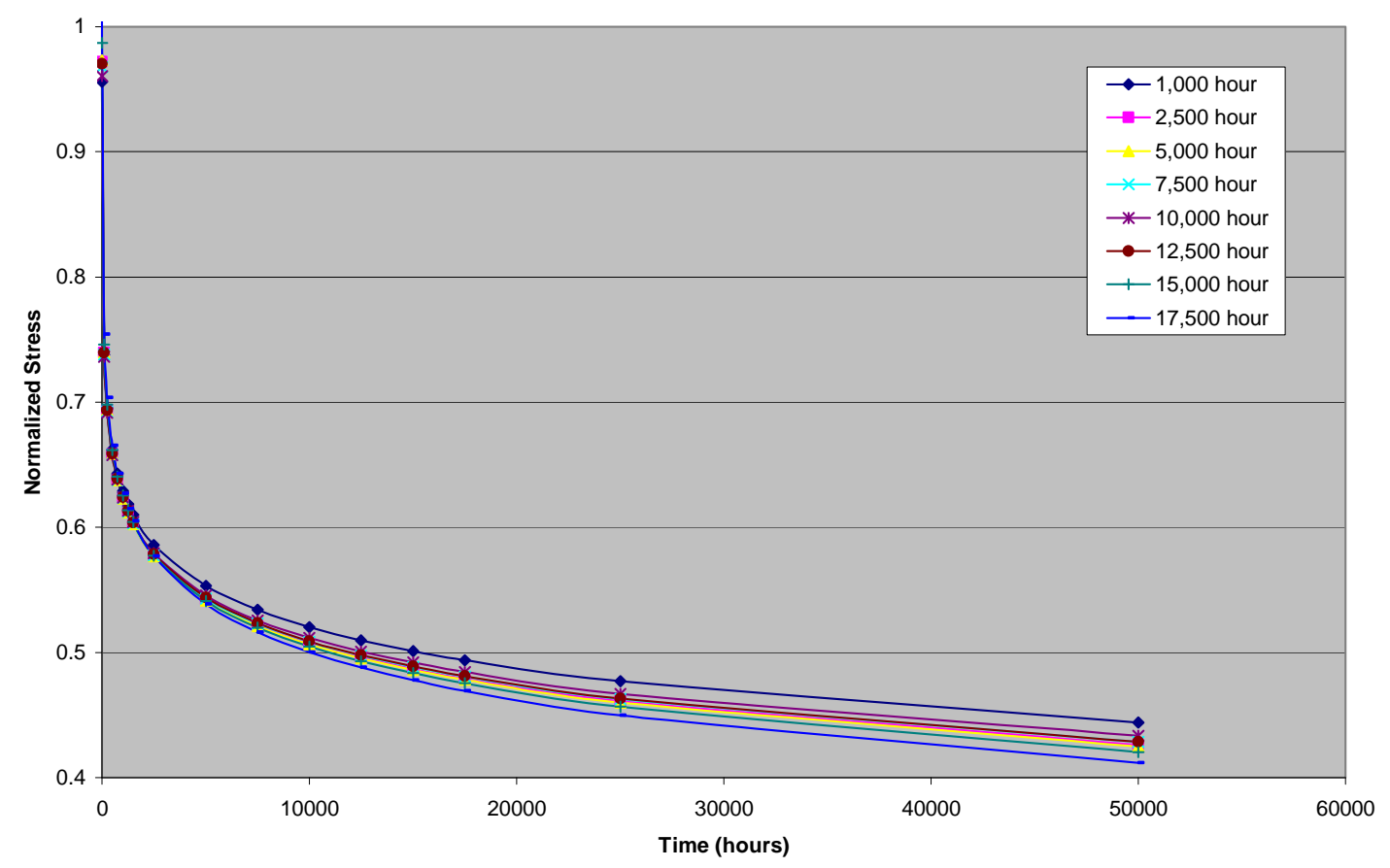

Figure 14. Gradient Test \#13 Log Fit Predictions (year four) 
Test \#15 Curve Fits

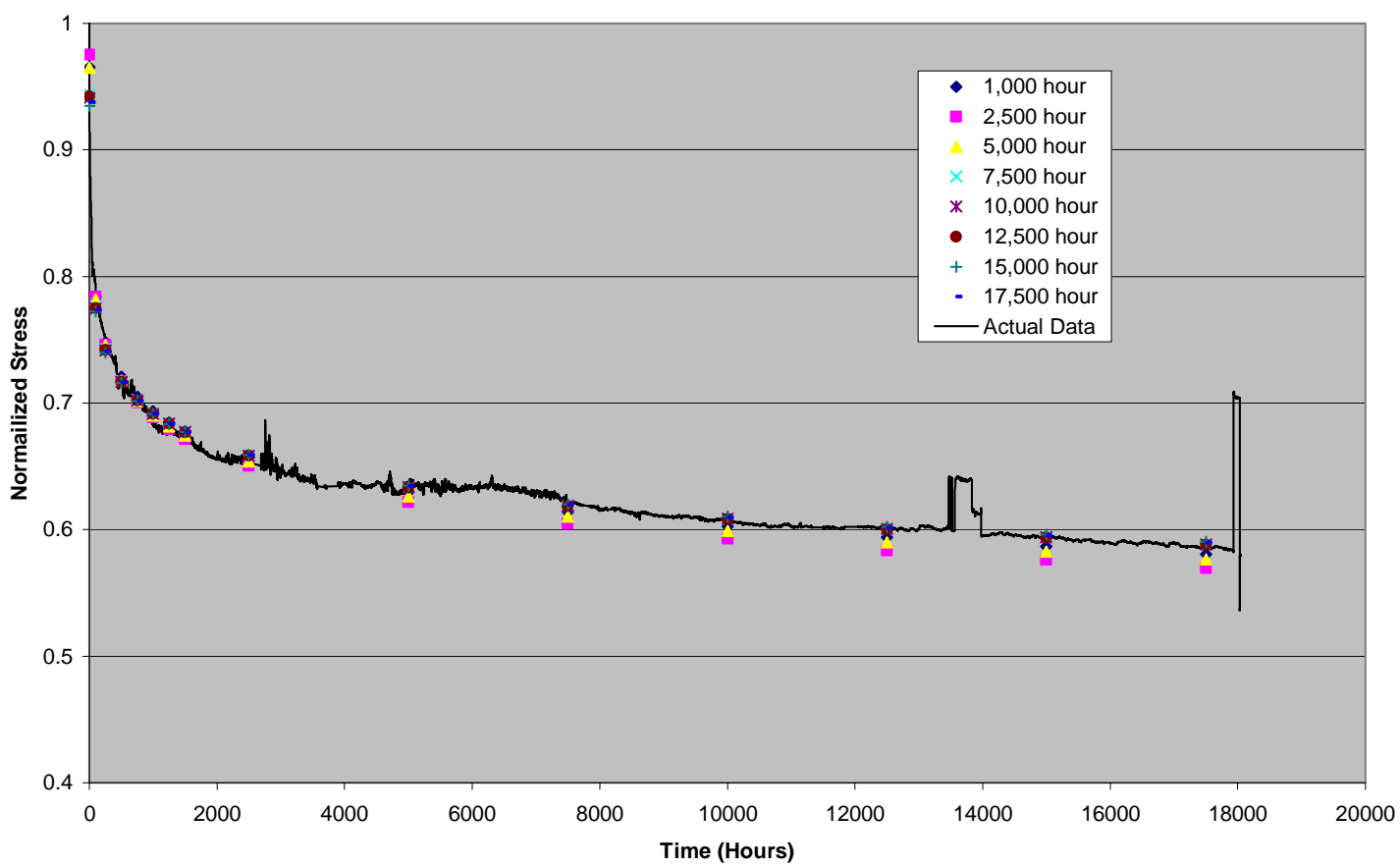

Test \#15 Curve Fits

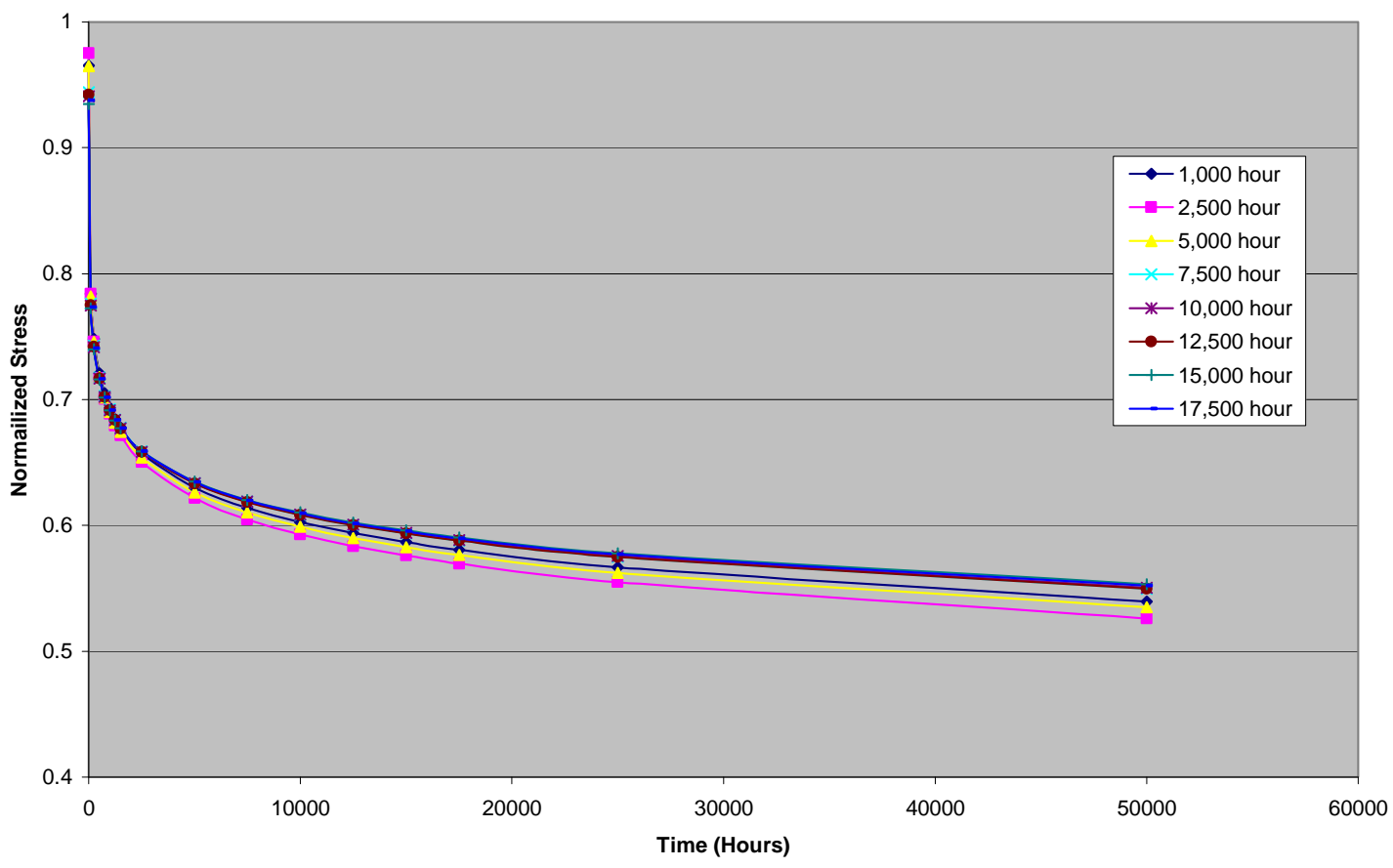

Figure 15. Gradient Test \#15 Log Fit Predictions (year four) 


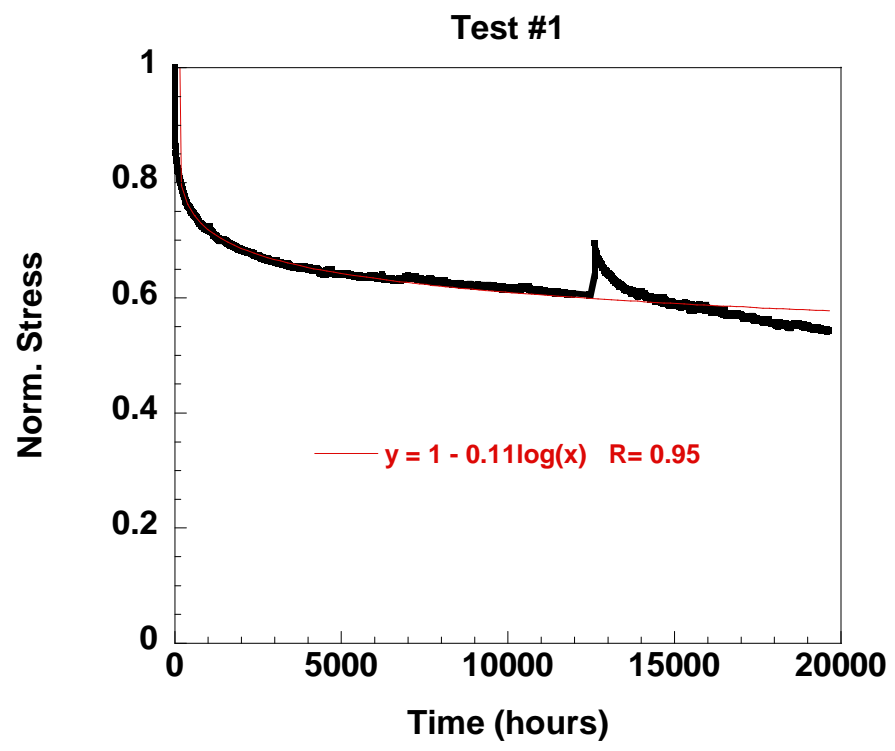

a)

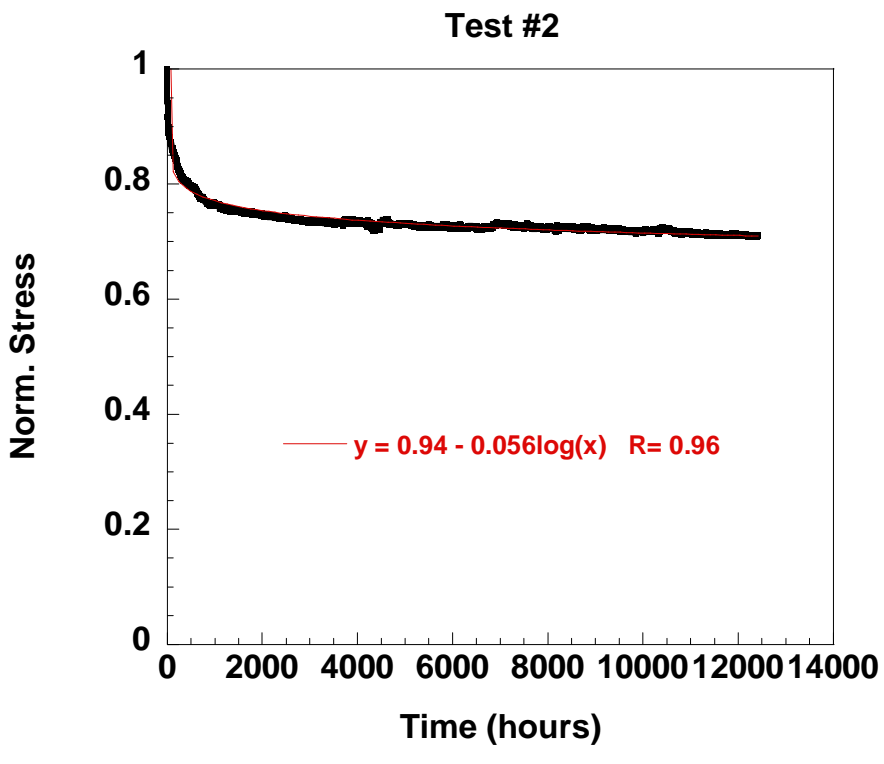

b) 


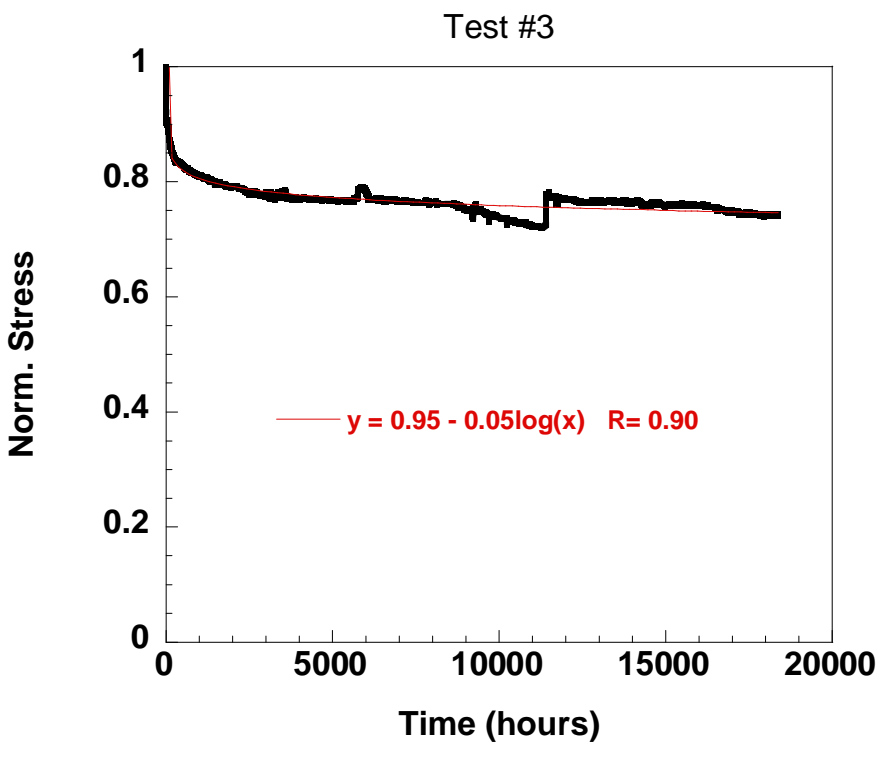

Figure 16. Log Function Curve Fits of Long-Term Gradient Stress Relaxation Data (a - Test \#1, b - Test \#2, c - Test \#3) 
Test \#1 Curve Fits

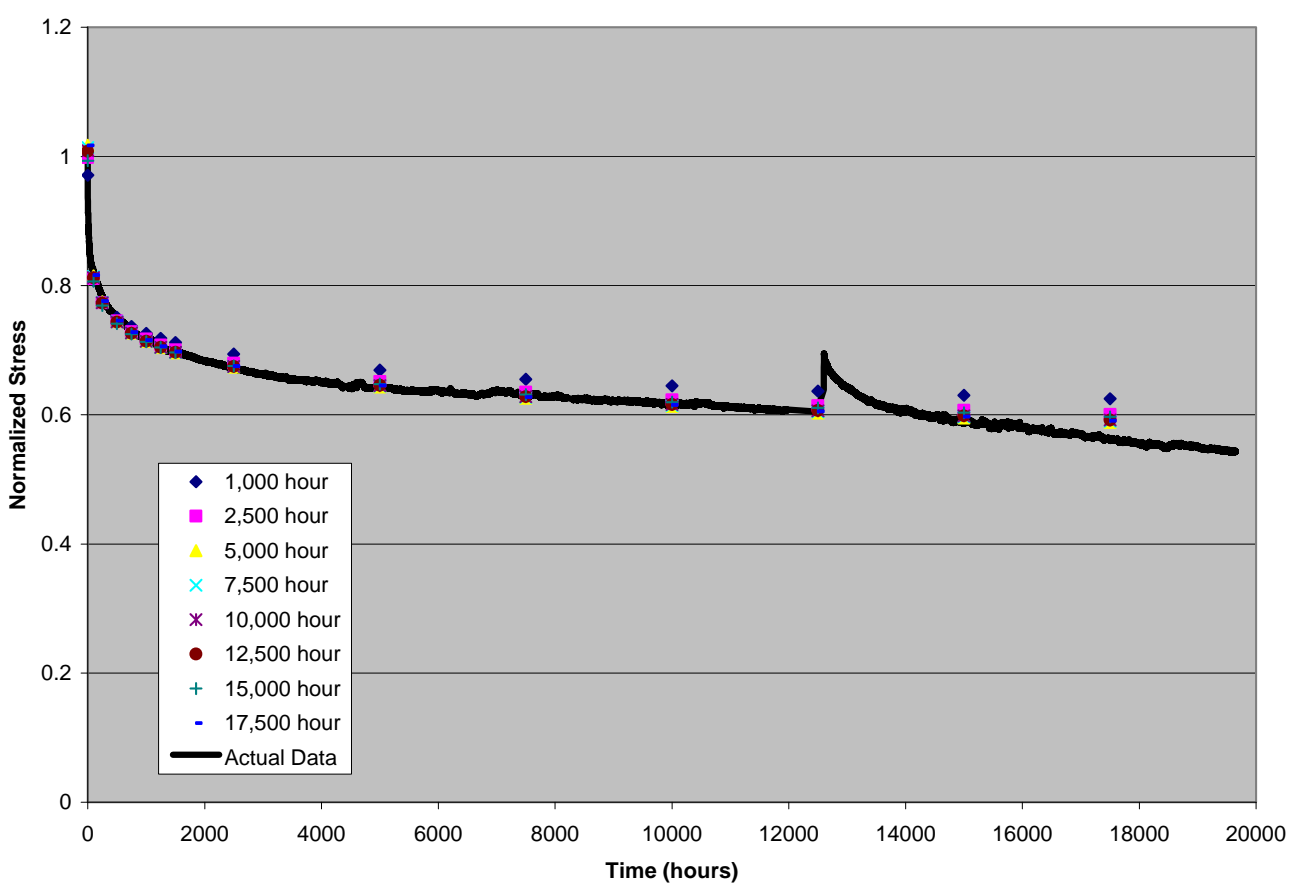

Test \#1 Curve Fits

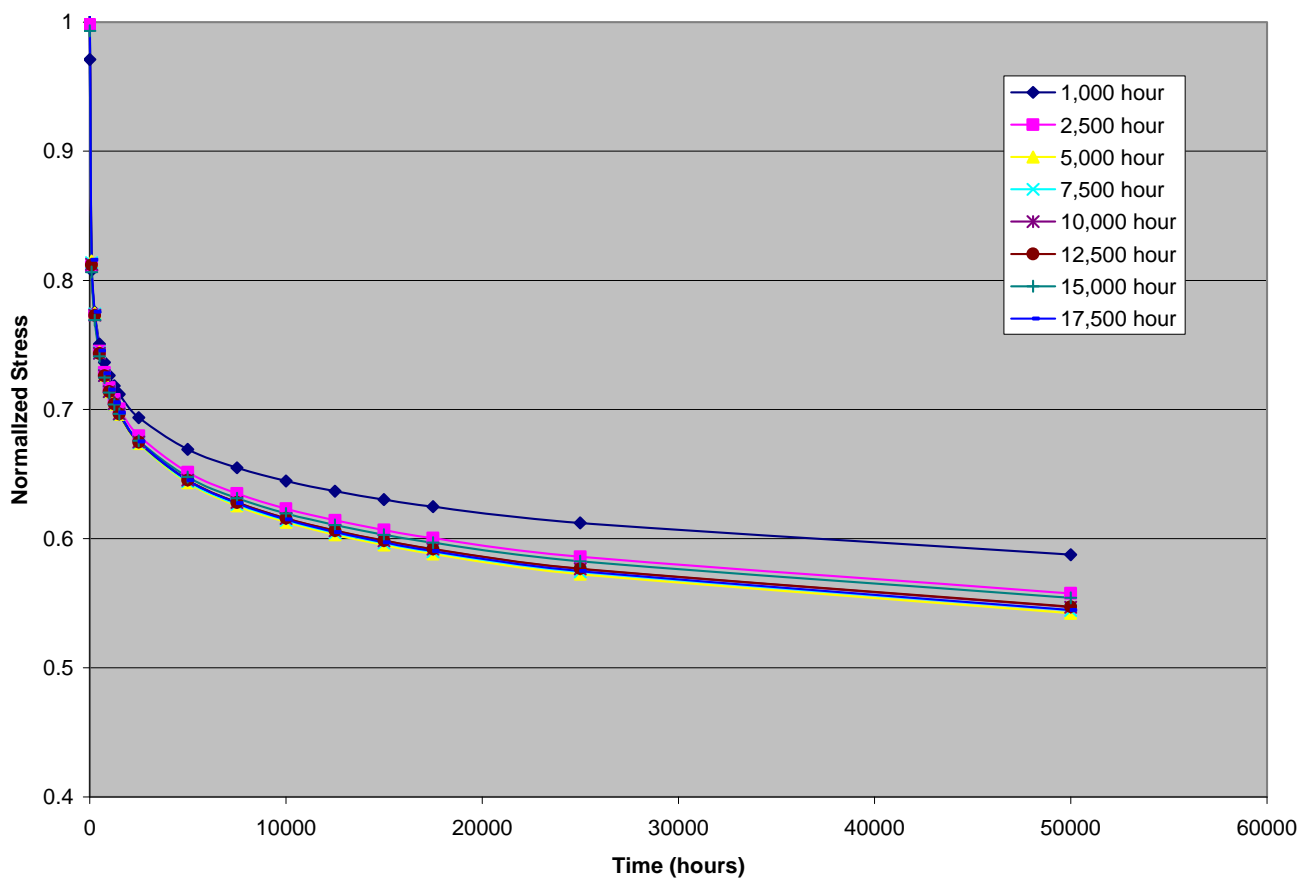

Figure 17. Gradient Test \#1 Log Fit Predictions (two year) 
Test \#2 Curve Fits

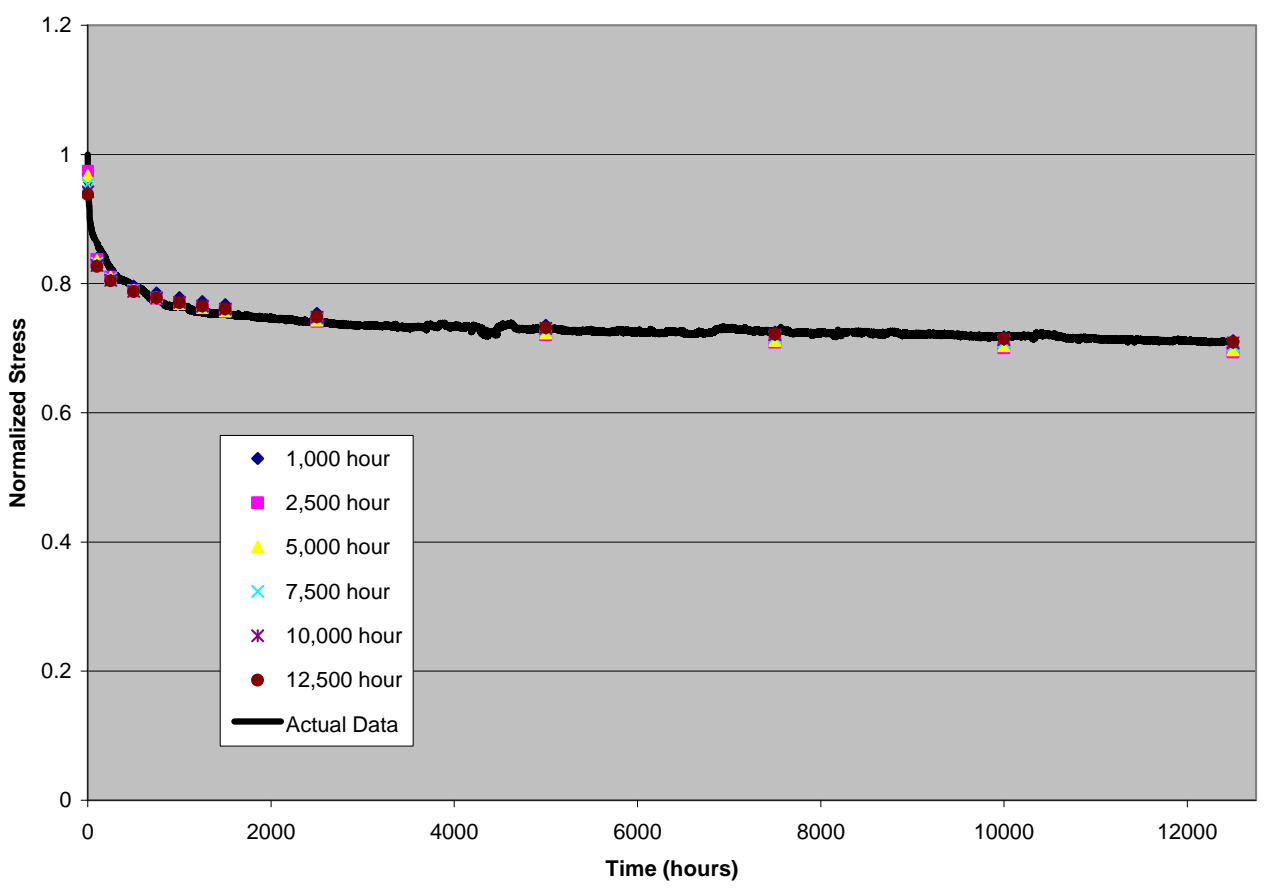

Test \#2 Curve Fits

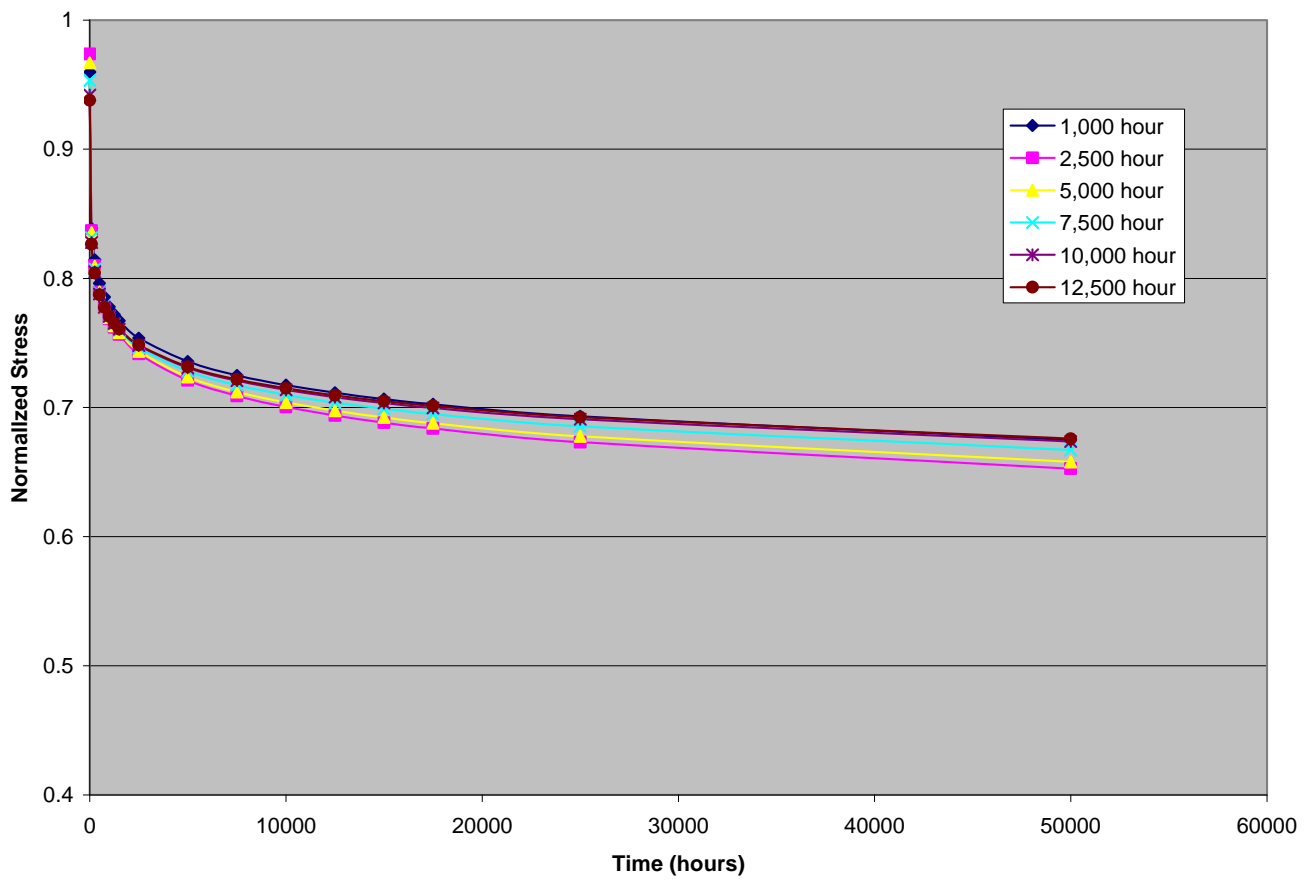

Figure 18. Gradient Test \#2 Log Fit Predictions (two year) 
Test \#3 Curve Fits

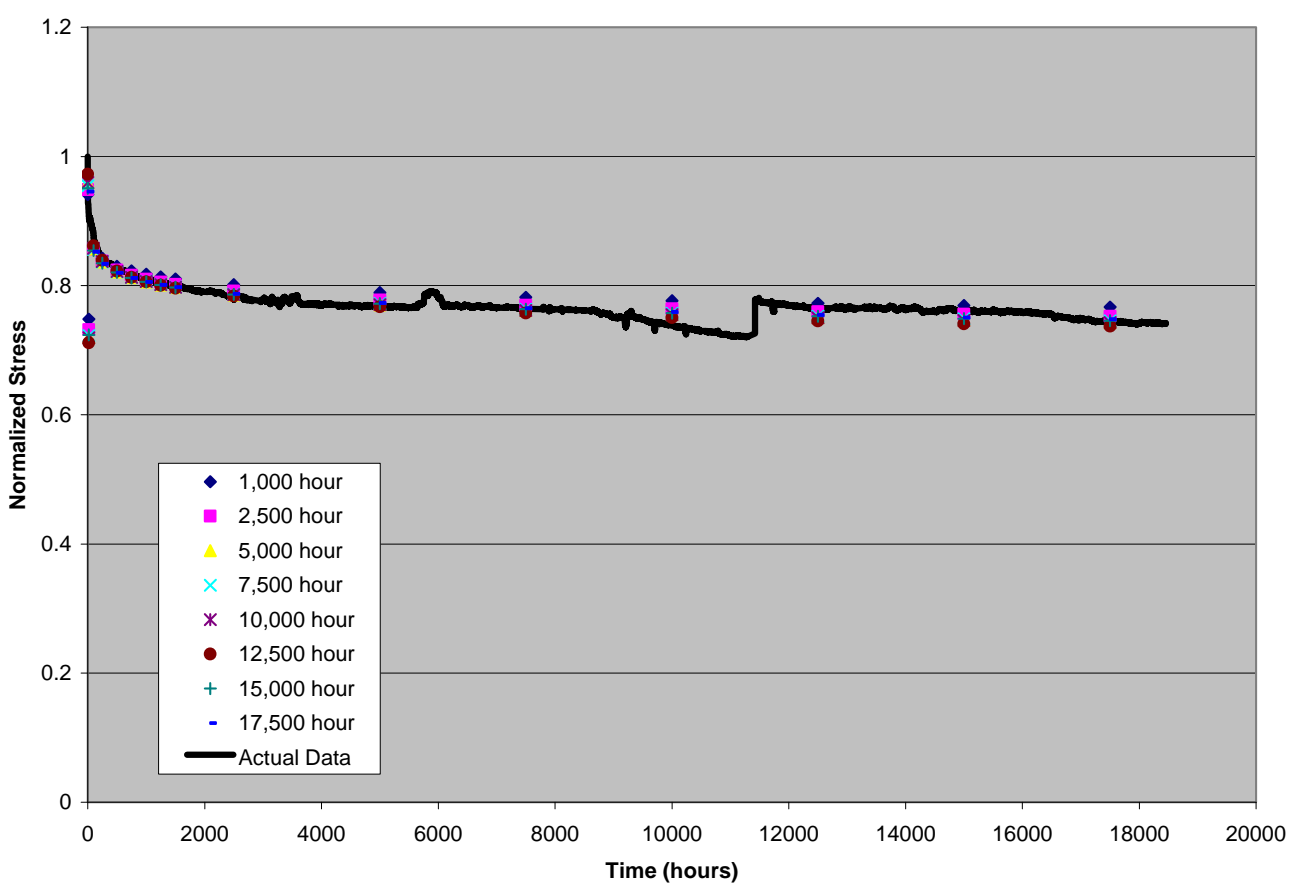

Test \#3 Curve Fits

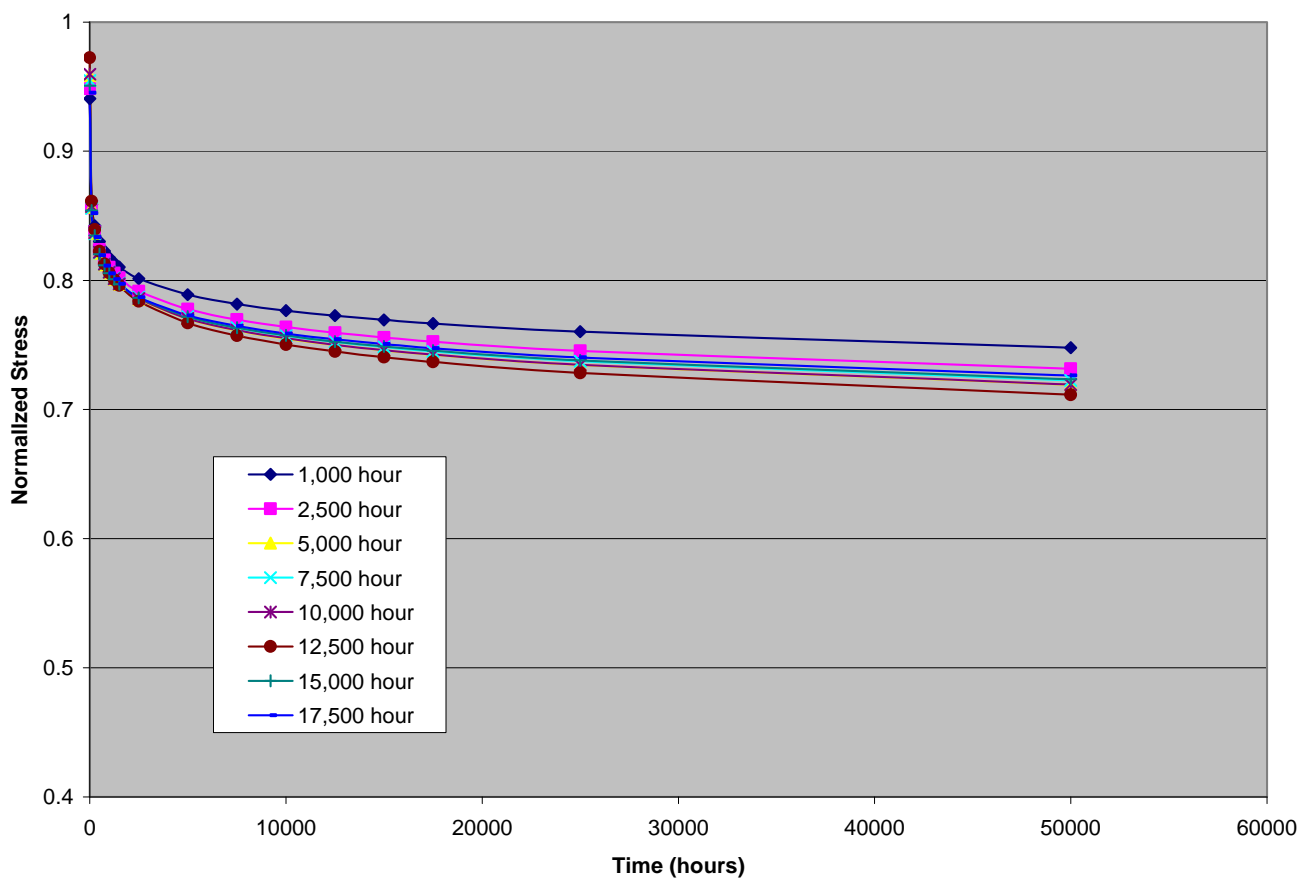

Figure 19. Gradient Test \#3 Log Fit Predictions (two year) 
Test \#15

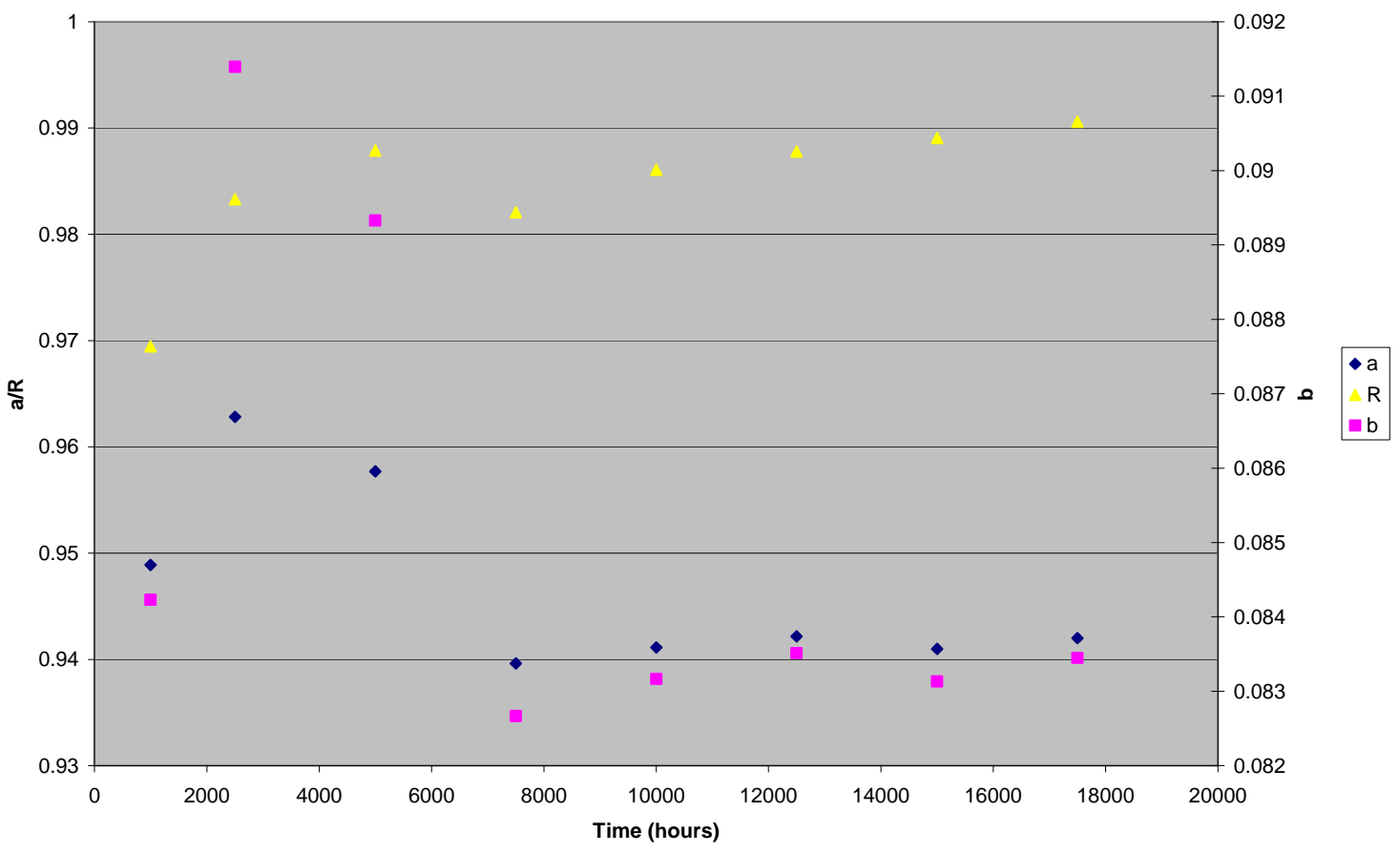

Test \#1

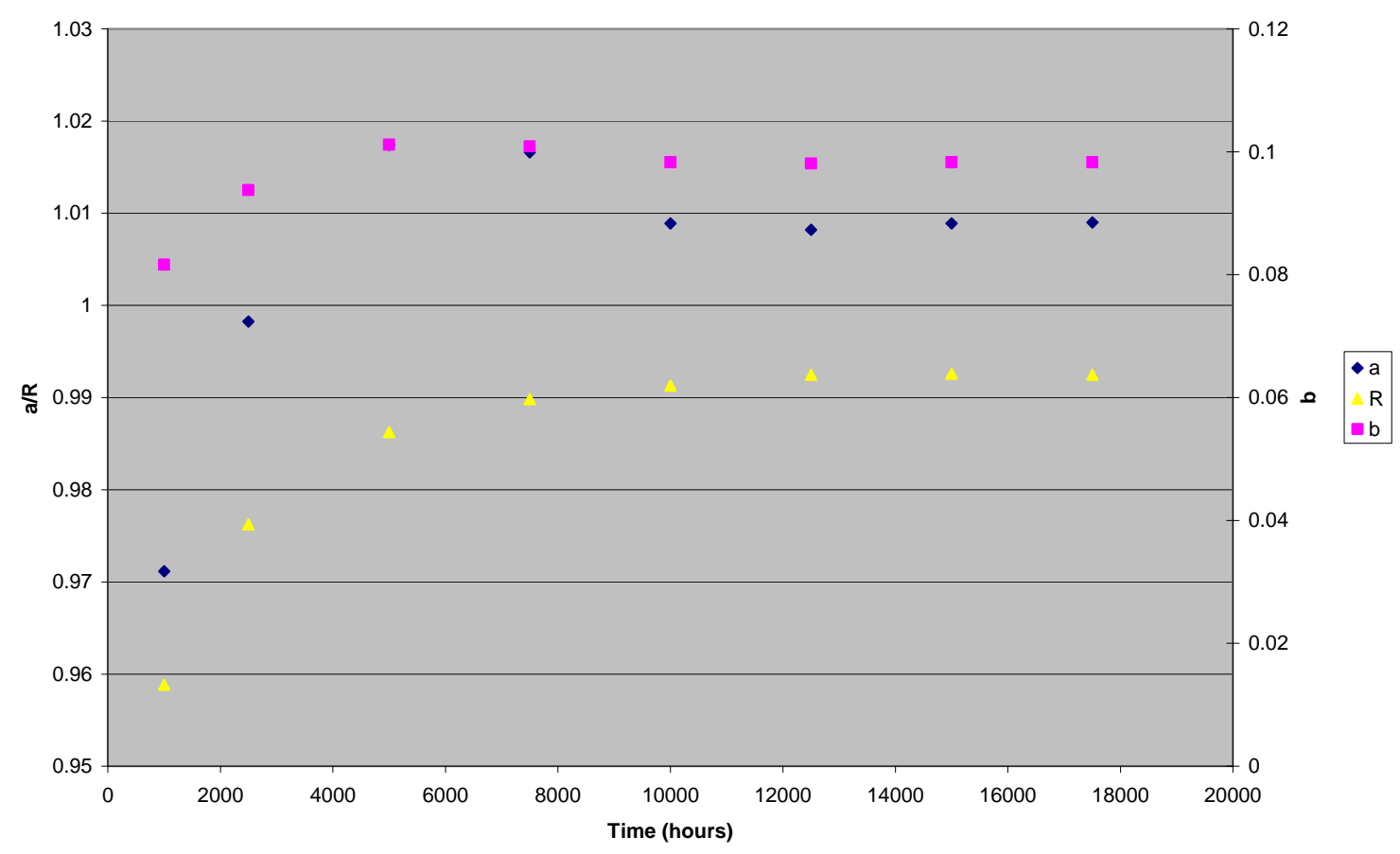


Test \#2

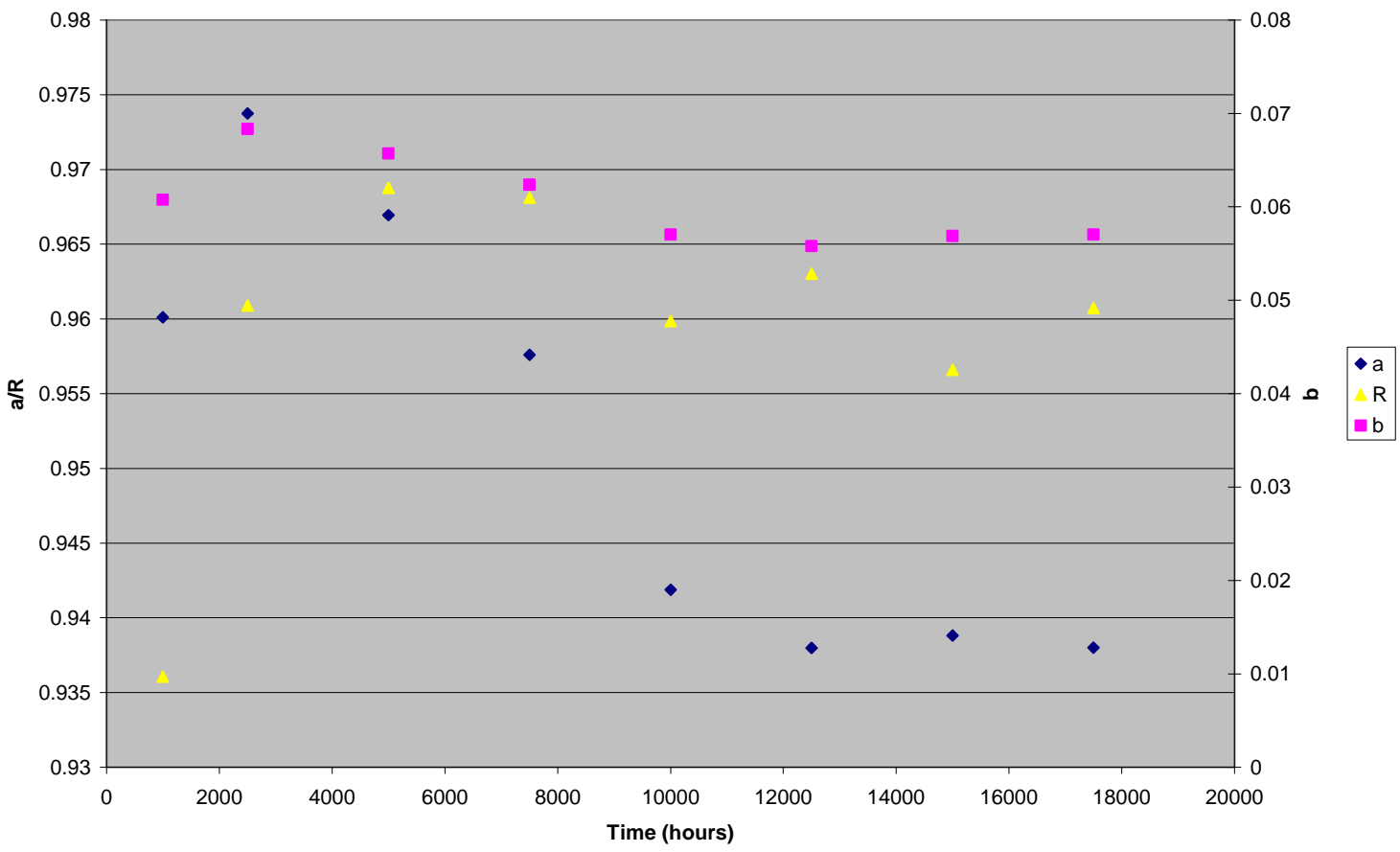

Figure 20. Change in Log-Log Fit Coefficients ( $a$ and b) and Fit Parameter (R) with Respect to Duration of Data Used for Curve Fit 
Appendix 1

Min-K Sample Densities with Respect to Batch Designations and Test Numbers

\begin{tabular}{|c|c|c|}
\hline Test & Batch & Density (g/in. ${ }^{3}$ ) \\
\hline \multicolumn{3}{|c|}{ Isothermal } \\
\hline Test \#1 & Batch \#1 & 5.42 \\
\hline Test \#2 & Batch \#1 & 5.06 \\
\hline Test \#3 & Batch \#1 & 5.29 \\
\hline Test \#4 & Batch \#1 & 5.46 \\
\hline Test \#5 & Batch \#1 & 5.36 \\
\hline Test \#6 & Batch \#1 & 5.23 \\
\hline Test \#7 & Batch \#1 & 5.14 \\
\hline Test \#8 & Batch \#1 & 5.14 \\
\hline Test \#9 & Batch \#1 & 5.19 \\
\hline Test \#10 & Batch \#1 & 5.21 \\
\hline Test \#11 & Batch \#1 & 5.19 \\
\hline Test \#12 & Batch \#1 & 5.09 \\
\hline Test \#13 & Batch \#1 & 5.23 \\
\hline Test \#14 & Batch \#1 & 5.31 \\
\hline Test \#15 & Batch \#1 & 5.31 \\
\hline Test \#16 & Batch \#1 & 5.45 \\
\hline Test \#17 & Batch \#1 & 5.42 \\
\hline Test \#18 & Batch \#2 & 5.20 \\
\hline Test \#19 & Batch \#1 & 5.19 \\
\hline Test \#20 & Batch \#2 & 5.24 \\
\hline \multicolumn{3}{|l|}{ Gradient } \\
\hline Test \#2 & Batch \#1 & - \\
\hline Test \#3 & Batch \#1 & 5.12 \\
\hline Test \#4 & Batch \#1 & 4.98 \\
\hline Test \#6 & Batch \#1 & 5.01 \\
\hline Test \#7 & Batch \#2 & 5.45 \\
\hline Test \#8 & Batch \#2 & 5.45 \\
\hline Test \#9 & Batch \#2 & 5.36 \\
\hline Test \#10 & Batch \#3 & 5.46 \\
\hline Test \#11 & Batch \#4 & 5.34 \\
\hline Test \#13 & Batch \#4 & 5.21 \\
\hline Test \#15 & Batch \#3 & 5.37 \\
\hline
\end{tabular}


ORNL/TM-2008/089

\section{INTERNAL DISTRIBUTION}

1. J.G. Hemrick

2. J.F. King

3. E. Lara-Curzio

4. George Ulrich

5. Suzanne Wilson

6. ORNL Technical Information Office (RC)

\section{EXTERNAL DISTRIBUTION}

7. Russell Bennett, Teledyne Energy Systems, 10707 Gilroy Road, Hunt Valley, MD 21031

8. Bob Carpenter, Orbital Sciences Corporation, 20030 Century Blvd., Suite 102, Germantown, MD 20874

9. John Dowicki, Office of Radioisotope Power Systems, NE-34/GTN, U.S. Department of Energy, 1000 Independence Avenue SW, Washington, DC 29585-1290

10. Michael Lauer, United Technologies, 6633 Canoga Avenue, Canoga Park, CA 91309

11. Kelly Lively, Idaho National Laboratory, P.O. Box 1625, Idaho Falls, ID 83415

12. Nora Low, United Technologies, 6633 Canoga Avenue, Canoga Park, CA 91309

13. Mike McKittrick, Teledyne Energy Systems, 10707 Gilroy Road, Hunt Valley, MD 21031

14. Office of Scientific and Technical Information (PDF file to ORNL Releasing Official, D.R. Hamrin)

15. Art Rabeau, Orbital Sciences Corporation, 20030 Century Blvd., Suite 102, Germantown, MD 20874

16. Emil Skrabek, Orbital Sciences Corporation, 20030 Century Blvd., Suite 102, Germantown, MD 20874

17. Scott Vogt, United Technologies, 6633 Canoga Avenue, Canoga Park, CA 91309

18. Bob Wiley, Office of Radioisotope Power Systems, NE-34/GTN, U.S.

Department of Energy, 1000 Independence Avenue SW, Washington, DC $29585-1290$ 